$23 / 2-1594$ y5(2)

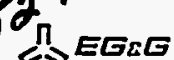

\title{
A MULTISPECTRAL SCANNER SURVEY OF THE IDAHO NATIONAL ENGINEERING LABORATORY AND THE HANFORD RESERVATION
}

\author{
Idaho and Washington
}




\section{DISCLAIMER}

This report was prepared as an account of work sponsored by an agency of the United States Government. Neither the United States Government nor any agency thereof, nor any of their employees, make any warranty, express or implied, or assumes any legal liability or responsibility for the accuracy, completeness, or usefulness of any information, apparatus, product, or process disciosed, or represents that its use would not infringe privately owned rights. Reference herein to any specific commercial product, process, or service by trade name, trademark, manufacturer, or otherwise does not necessarily constitute or imply its endorsement, recommendation, or favoring by the United States Government or any agency thereof. The views and opinions of authors expressed herein do not necessarily state or reflect those of the United States Government or any agency thereof. 


\section{DISCLAIMER}

Portions of this document may be illegible in electronic image products. Images are produced from the best available original document. 


\title{
A MULTISPECTRAL SCANNER SURVEY OF THE IDAHO NATIONAL ENGINEERING LABORATORY AND THE HANFORD RESERVATION
}

\author{
Idaho and Washington
}

DATE OF SURVEY: NOVEMBER 1993

S.B. Brewster, Jr.

M.E. Howard

J.E. Shines

Project Scientists

The DOE Remote Sensing Laboratory Operated for the U.S. Department of Energy by

EG\&G Energy Measurements, inc.

Las Vegas, Nevada

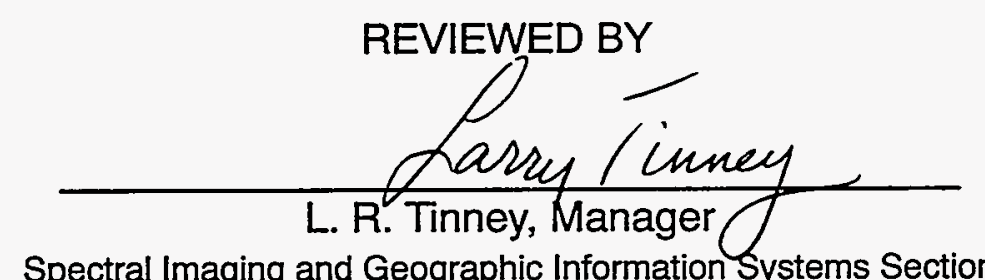

Spectral Imaging and Geographic Information Systems Section

This Document is UNCLASSIFIED

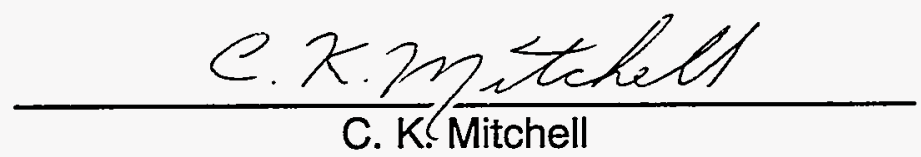

Classification Officer

This work was performed by EG\&G/EM for the United States Department of Energy under Contract Number DE-AC08-93NV11265. 


\section{ACKNOWLEDGEMENT}

Special thanks to William M. Quam, Project Coordinator for the Big O experiment, for his technical assistance with this survey. Bill coordinated the data collection effort and provided oversight of the analysis and report preparation. 


\begin{abstract}
An airborne multispectral scanner survey of selected sites on the Idaho National Engineering Laboratory and the Hanford Reservation was performed in mid-November 1993. Aerial multispectral scanner and photography data were acquired coincidentally with the Big $\mathrm{O}$ experiment at both locations. To illustrate two potential applications, the multispectral scanner data were digitally enhanced to facilitate the detection of soil disturbance and evidence of surface water transport. The main conclusion of this study was that multispectral data acquired under these conditions can be useful for soil disturbance detection. The imagery did not prove as useful, however, for direct indications of surface water transport. It was possible to infer some water transport patterns from dry water beds, but only if surface indications were present.
\end{abstract}




\section{CONTENTS}

Acknowledgement $\ldots \ldots \ldots \ldots \ldots \ldots \ldots \ldots \ldots \ldots \ldots \ldots \ldots \ldots \ldots \ldots \ldots \ldots \ldots \ldots \ldots \ldots \ldots \ldots$

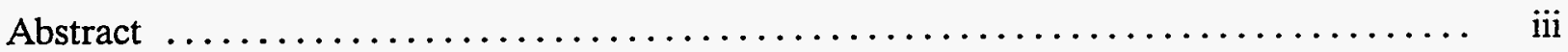

\section{Sections}

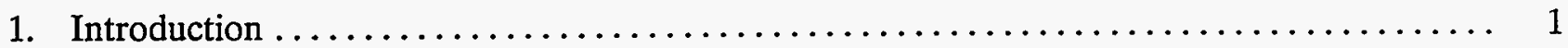

1.1 Site Locations and Background $\ldots \ldots \ldots \ldots \ldots \ldots \ldots \ldots \ldots \ldots \ldots \ldots \ldots \ldots \ldots \ldots \ldots \ldots \ldots \ldots$

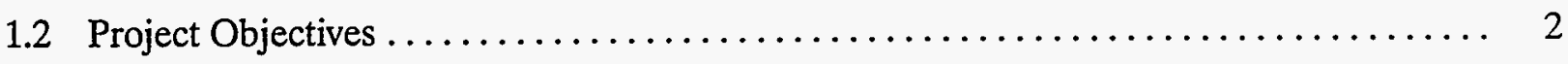

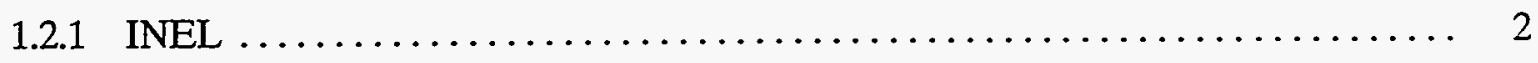

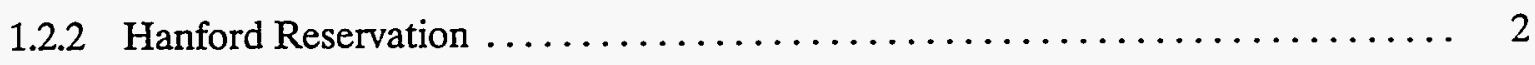

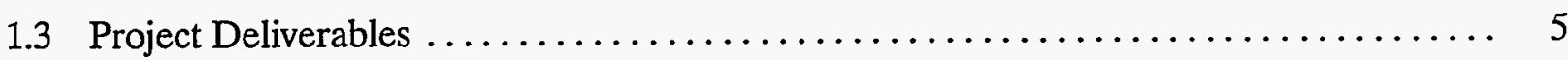

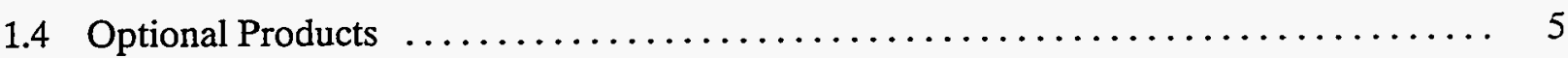

2. Multispectral Scanner System $\ldots \ldots \ldots \ldots \ldots \ldots \ldots \ldots \ldots \ldots \ldots \ldots \ldots \ldots \ldots \ldots \ldots$

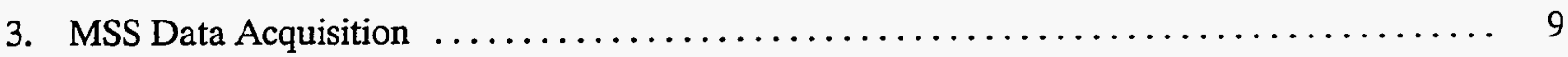

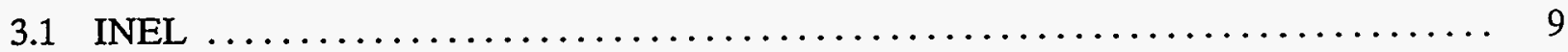

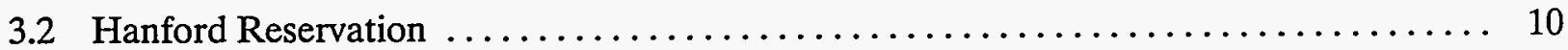

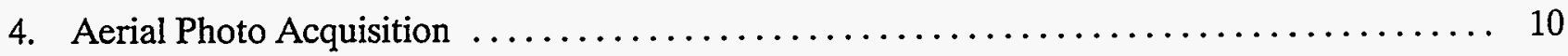

5. MSS and Aerial Photography Data Summaries $\ldots \ldots \ldots \ldots \ldots \ldots \ldots \ldots \ldots \ldots \ldots \ldots$

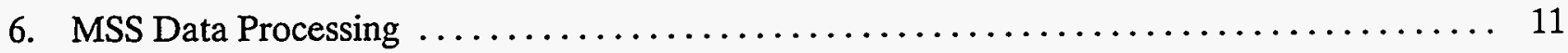

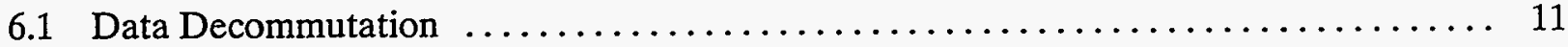

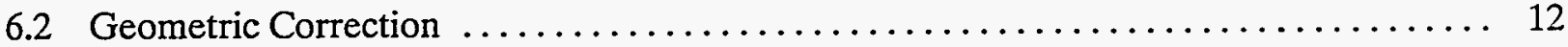

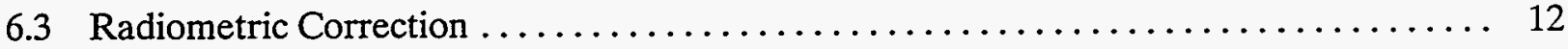

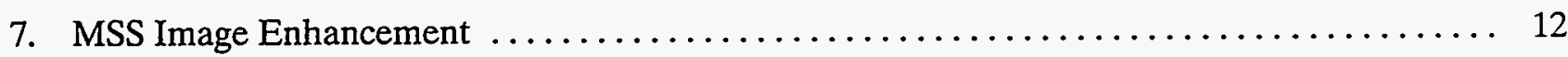

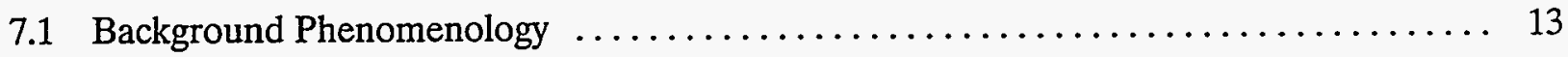

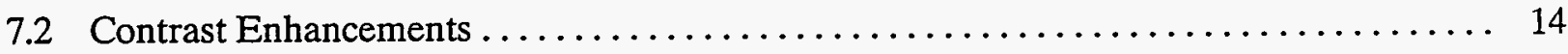

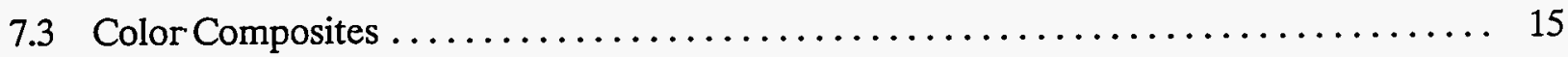

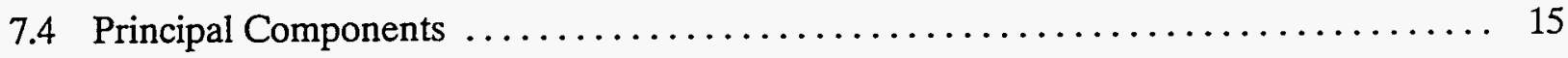

7.5 Geologic Ratio Enhancement $\ldots \ldots \ldots \ldots \ldots \ldots \ldots \ldots \ldots \ldots \ldots \ldots \ldots \ldots \ldots \ldots$

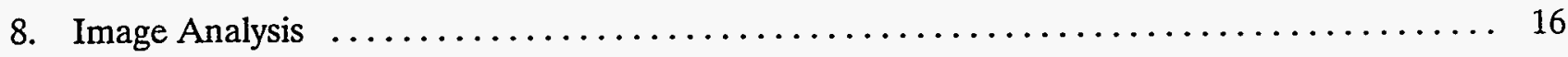

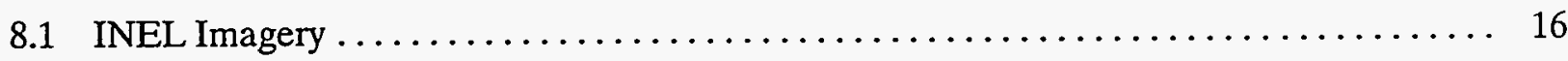




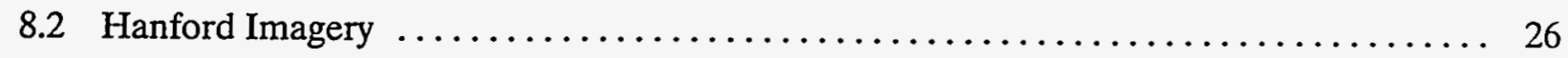

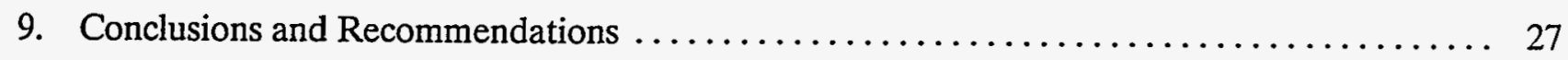

Figures

1 Idaho National Engineering Laboratory (INEL) Survey Location Map $\ldots \ldots \ldots \ldots \ldots \ldots$

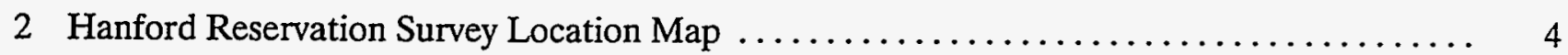

3 Daedalus AADS1268 Multispectral Scanner System Optical Diagram ................ 8

4 Idaho Chemical Processing Plant (ICPP - INEL) (SIGIS \#94215.06) . . . . . . . . . . 17

5 Radiation Waste Management Center (RWMC - INEL) (SIGIS \#94215.07) $\ldots \ldots \ldots \ldots, 18$

6 Train Decontamination Area (Hanford) (SIGIS \#94215.08) .................... 19

7200 East Color Simulation and Thermal Mosaic (Hanford) (SIGIS \#94215.09) . . . . . . . 20

8 ICPP Disturbed Earth Enhancement (INEL) (SIGIS \#94215.01) $\ldots \ldots \ldots \ldots \ldots \ldots \ldots, 21$

9 ICPP Principal Components Enhancement (INEL) (SIGIS \#94215.02 ............. 22

10 ICPP Thermal Composite (INEL) (SIGIS \#94215.03) $\ldots \ldots \ldots \ldots \ldots \ldots \ldots \ldots \ldots \ldots \ldots$

11 RWMC Disturbed Earth Enhancement (INEL) (SIGIS \#94215.04) ............... 24

12 RWMC Geologic Enhancement (INEL) (SIGIS \#94215.05) .................... 25

\section{Tables}

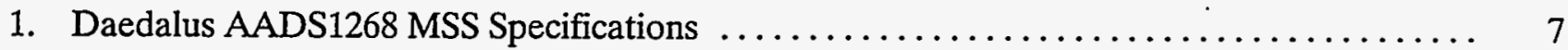

2. Measured Spectral Sensitivity of Daedalus AADS1268 MSS System $\ldots \ldots \ldots \ldots \ldots \ldots \ldots$

\section{Appendices}

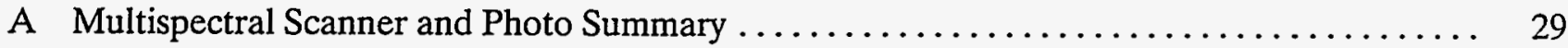

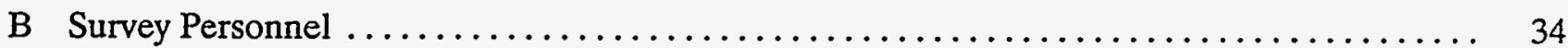

References $\ldots \ldots \ldots \ldots \ldots \ldots \ldots \ldots \ldots \ldots \ldots \ldots \ldots \ldots \ldots \ldots \ldots \ldots \ldots \ldots \ldots \ldots, 35$ 


\section{INTRODUCTION}

An airborne multispectral scanner (MSS) survey of portions of the Idaho National Engineering Laboratory (INEL) and the Hanford Reservation was accomplished during November 1993. The MSS survey was made in support of the Big O experiment, which was designed to test the airborne gamma ray detection system developed by EG\&G Energy Measurements, Inc. (EG\&G/EM), under the direction of the Office of Arms Control. Aerial MSS and photography data were acquired coincidentally with the BIG O radiation survey at both locations. The survey was conducted by the Spectral Imaging and Geographic Information Systems (SIGIS) Section of the Remote Sensing Laboratory (RSL) which is operated by EG\&G/EM for the U.S. Department of Energy, Nevada Operations Office (DOE/NV).

\subsection{Site Locations and Background}

The INEL site was established in 1949 as the National Reactor Testing Station to provide an isolated station where various kinds of nuclear reactors and support facilities could be built. The facilities were used primarily to demonstrate that nuclear energy could be safely harnessed for generating electricity and other peaceful uses. More nuclear reactors have been built at the INEL site than at any other location.

The INEL site is located on the Upper Snake River Plain in southeastern Idaho at an average elevation of $4,500 \mathrm{ft}(1,500 \mathrm{~m})$. The site covers approximately $888 \mathrm{mi}^{2}\left(2,300 \mathrm{~km}^{2}\right)$, extending $39 \mathrm{mi}(63 \mathrm{~km})$ from north to south. It is $36 \mathrm{mi}(58 \mathrm{~km})$ wide at its broader southern part. The INEL site is approximately $22 \mathrm{mi}(35 \mathrm{~km})$ west of Idaho Falls.

The Hanford Reservation was selected by the Army Corps of Engineers in 1943 for producing nuclear materials. Under the Manhattan Project, the production of plutonium was in support of the United States nuclear efforts in World War II. Since that time, the Hanford site has been used for the production of nuclear materials and electricity, diverse research activities, and waste management operations.

The Hanford Reservation lies within the semiarid Pasco Basin, part of the Columbia Plateau in southeastern Washington. The site occupies an area of about $580 \mathrm{mi}^{2}\left(1,500 \mathrm{~km}^{2}\right), 30 \mathrm{mi}(48 \mathrm{~km})$ north to south and $24 \mathrm{mi}(38 \mathrm{~km})$ east to west. The Columbia River flows through the northern part of the site, and turning south it forms part of its eastern boundary. The Yakima River runs along part of the southern 
boundary and joins the Columbia River near the city of Richland. The cities of Richland, Kennewick, and Pasco (the Tri-Cities) are the nearest population center, located approximately $4 \mathrm{mi}(7 \mathrm{~km})$ southeast of the site.

\subsection{Project Objectives}

\subsubsection{INEL}

The objectives for the mission at INEL were to acquire high spatial resolution (approximately 1 meter per pixel) MSS data and color aerial photography at five sites: the Idaho Chemical Processing Plant (ICPP), the Radiation Waste Management Center (RWMC), the Test Reactor Area (TRA), and two buried waste sites (Borax-1 and SL-1) (Figure 1).

A lower priority objective, to facilitate data integration, was to acquire single-frame photo coverage over each of the five sites. For this, the three larger sites required a flight line at a higher altitude. Ground data collection objectives also required an additional flight line over both the reflectance targets and the water body used for thermal calibration of the MSS data. The flight was to be repeated during the predawn (twilight) hour for thermal data acquisition.

\subsubsection{Hanford Reservation}

The prime objective for the MSS/photo survey at Hanford was to acquire data over six facilities: three reactors $(100 \mathrm{~B} \& \mathrm{C}, 100 \mathrm{KE} \& \mathrm{KW}$, and $100 \mathrm{~N})$ and three chemical processing plants $(200 \mathrm{~W}, 200 \mathrm{E}$, and $200 \mathrm{~N})$. The sites were flown at the lowest altitude allowable for nighttime conditions, at 2,500 $\mathrm{ft}(975 \mathrm{~m})$ above ground level (AGL).

A secondary priority was a portion of the Columbia River which runs from west to east past the reactor facilities through the bend where the river turns southward, extending as far south as the city of Richland. The river was covered with three, single-line legs at 10,000 ft (3,000 m) AGL. Higher altitude, singleframe photos of the larger sites were not attempted because suitable photos for data integration were collected in the summer of 1993 (Figure 2). 


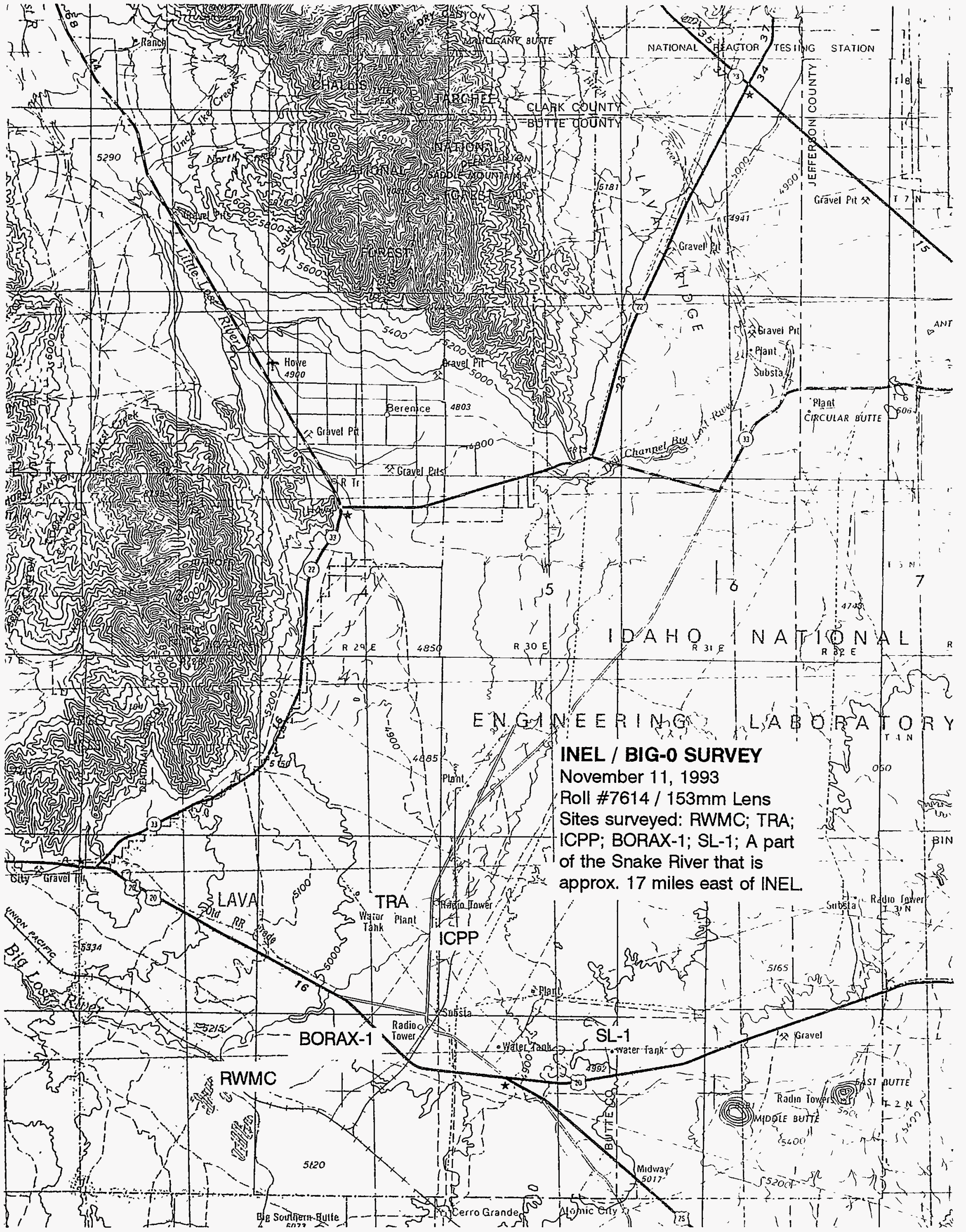




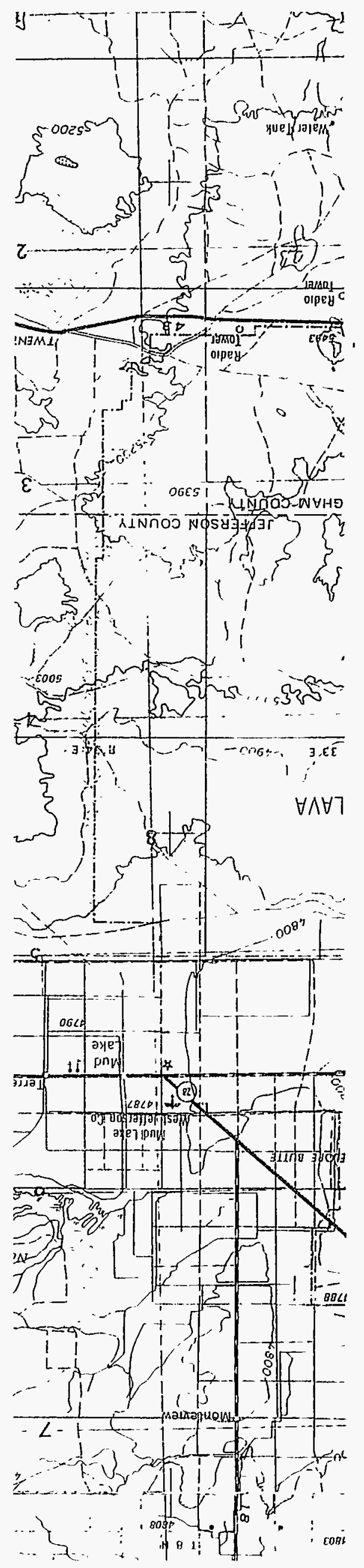




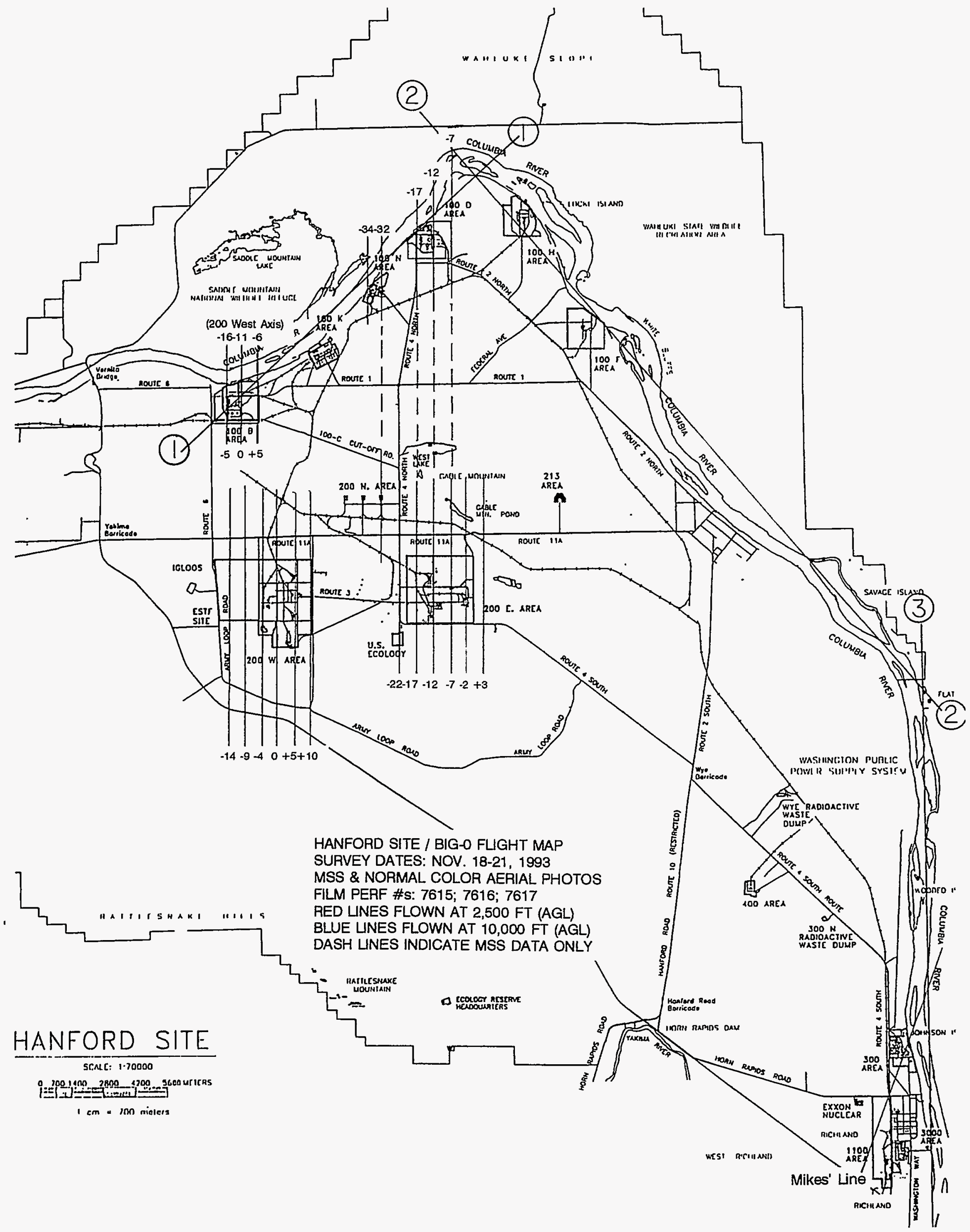


Ground data acquisition required an extra flight line over the reflectance targets and one flight line over a collection point along the river for thermal calibration. The flight line over the river was repeated during the predawn.

The scope of the aerial acquisition at Hanford was considerably greater than that at INEL, and the use of the Microwave Ranging Station (MRS) navigation system was essential for nighttime flying. Because of the larger scope, it was necessary to consider true nighttime as the predawn flight window, rather than the twilight period when daytime flight rules could be followed.

\subsection{Project Deliverables}

Standard project deliverables for an MSS and photographic survey include a proof set of the aerial photographs and a mission summary report. In addition, selected photographs can be copied and enlargements made. Digital tapes of the MSS imagery can be provided in a variety of standard image processing system formats. This mission summary report includes the following:

- Summary description of the MSS and aerial photographic mission at the INEL site and Hanford Reservation.

- Brief overview of the scanner system and data format.

- Description of the analysis procedures used to prepare sample image enhancements.

- Sample MSS color composites from two areas at the INEL site including enhancements for potential surface water movement and selected channel combinations used for disturbance detection.

- Sample MSS color composites from two areas at the Hanford Reservation using enhancements similar to those described above.

\subsection{Optional Products}

Proof books of the aerial photographs are available from RSL. Specific photos in these books can be identified by the unique roll and frame identifier imprinted along the top edge of the photo. Original 
photography is archived at RSL, and copies and enlargements of any aerial photographs can be produced by the RSL Photo/Video Section.

MSS imagery can be processed for a wide variety of applications. Products may be requested in digital form (data in tape or optical disk format), photographically produced images such as are presented with this report, or in standard report form. Some products can be prepared with a minimum of direction from the end-user; others may require a great amount of interaction with site personnel and/or scientists from other disciplines, and may require site visits by the image analyst.

The selected examples of MSS data presented in this report illustrate the value of MSS imagery for detecting soil disturbance areas in arid environments. Questions regarding additional analysis and products or similar surveys may be directed to the RSL SIGIS Manager or the Remote Sensing Division Director.

\section{MULTISPECTRAL SCANNER SYSTEM}

The Daedalus AADS1268 MSS is an airborne electro-optical scanner system of proven quality and usefulness in the remote sensing community. It is one of three similar instruments maintained and operated by the RSL for DOE. These MSS systems are flown on a regular basis with the collected data used for a variety of applications.

The manufacturer's system specifications for the instrument flown during the this survey are summarized in Table 1. The measured channel sensitivities are listed in Table 2.

The scanner contains four detector packages with a total of eleven discrete elements (Figure 3). Reflected and/or emitted electromagnetic energy enters the scanner from the bottom and strikes a rotating "axe-blade" mirror. This mirror reflects the energy into the detector housing, where a prism and a series of dichroic filters spectrally decompose the energy onto the detectors.

Channels 1-8 are generated by a single silicon detector array, which is contained in an integrated circuit-like package. Channels 9 and 10 are generated by separate detectors. A thermal infrared (IR) detector that generates channels 11 and 12 resides inside a dewar that is filled with liquid nitrogen to increase its sensitivity. 


\begin{tabular}{|l|l|}
\hline \multicolumn{2}{|c|}{ Table 1. Daedalus AADS1268 MSS Specifications } \\
\hline Number of Channels & 12 \\
Operating Wavelengths & $0.42 \mu \mathrm{m}$ to $12.5 \mu \mathrm{m}$ \\
Scan Rate & $12.5,25,50$, or 100 scans/second (selectable) \\
Instantaneous Field of View (IFOV) & 2.5 milliradians (1.25 mrad half-angle mode) \\
Total Field of View (FOV) & 85.92 degrees \\
Temperature Resolution & 0.1 centigrade \\
Roll Correction & \pm 15 degrees \\
Reference Sources & Infrared: two controllable, thermal blackbodies \\
Video Words/Scan Line & 716 \\
Digitizer Gains & $0.5,1,2,4$, or 8 (selectable) \\
\hline
\end{tabular}

\begin{tabular}{|c|c|c|}
\hline $\begin{array}{l}\text { Channel } \\
\text { Number }\end{array}$ & Wavelength $(\mu \mathrm{m})$ & Color Spectrum \\
\hline 1 & $0.42-0.44$ & Violet/Blue \\
\hline 2 & $0.46-0.51$ & Blue/Green \\
\hline 3 & $0.52-0.59$ & Green/Yellow \\
\hline 4 & $0.59-0.62$ & Orange \\
\hline 5 & $0.62-0.67$ & Red \\
\hline 6 & $0.67-0.72$ & Near Infrared \\
\hline 7 & $0.73-0.85$ & Near Infrared \\
\hline 8 & $0.84-0.97$ & Near Infrared \\
\hline 9 & $1.59-1.79$ & Middle Infrared \\
\hline 10 & $2.1-2.4$ & Middle Infrared \\
\hline 11 & $8.28-10.67$ & Thermal Infrared \\
\hline 12 & $8.28-10.67$ & Thermal Infrared \\
\hline \multicolumn{3}{|c|}{ Alternate Configuration } \\
\hline 10 & - & - \\
\hline 11 & $3.16-5.20$ & Thermal Infrared \\
\hline 12 & $8.28-10.67$ & Thermal Infrared \\
\hline
\end{tabular}




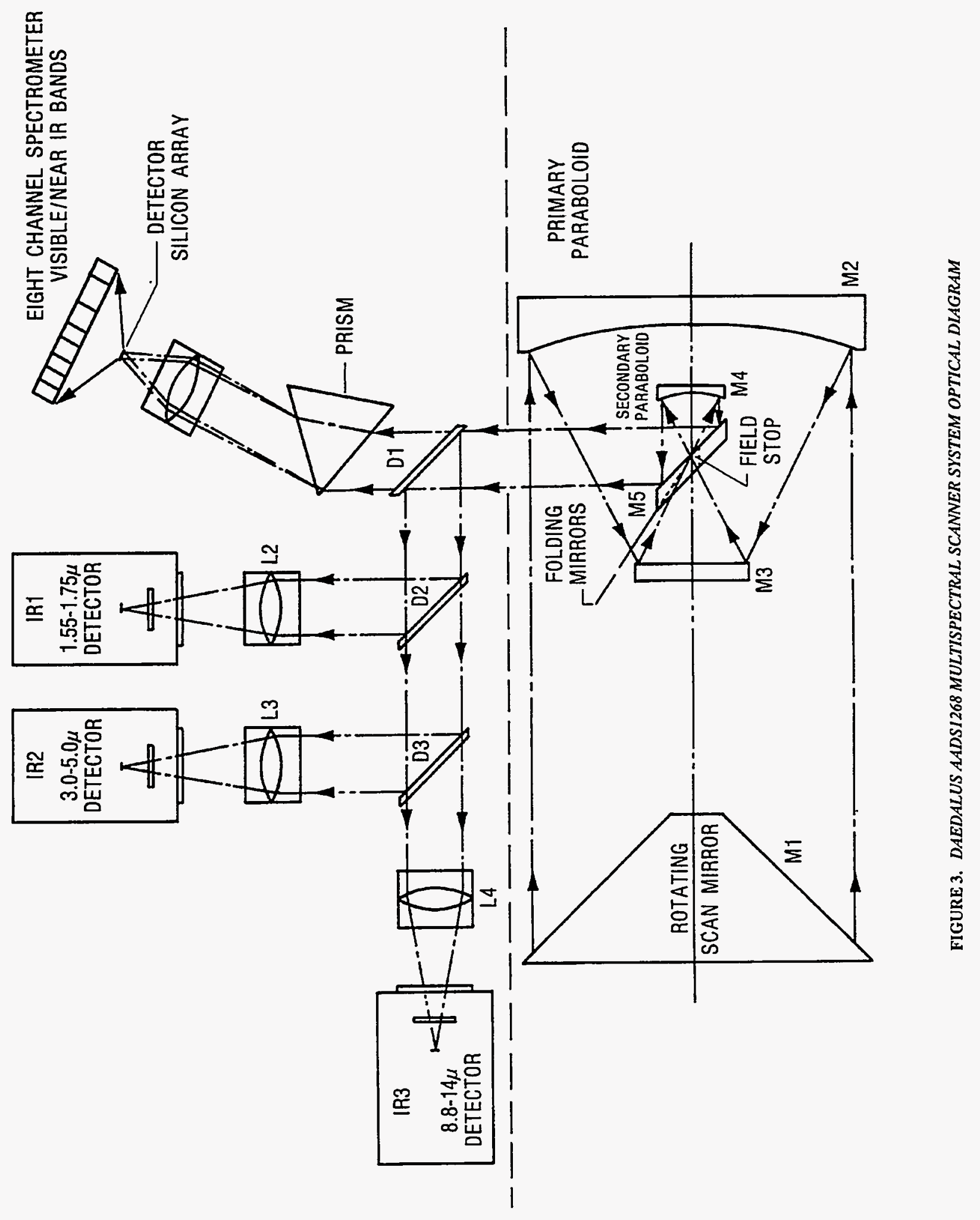


Electromagnetic energy striking the detectors produces a photovoltaic effect proportional to the number of photons striking at a given instant. The signal is amplified and converted into an 8-bit digital value, which is then recorded onto a high-density digital tape (HDDT). The resulting spatial array of data represents a two-dimensional image proportional to the reflectance or emitted energy of the scene features. The scanner has selectable scan rates (up to 100 scan lines per second), which are necessary to assure contiguous coverage from different altitudes and relative ground speeds.

\section{MSS DATA ACQUISITION}

\subsection{INEL}

The aerial survey was flown with a Convair 580 twin-engine airplane, modified with ports in the floor to accommodate remote sensing equipment. The aircraft was configured with the MSS in one port and a large-format aerial camera in the other.

The MSS and photo survey objectives were met. All of the high-priority and secondary objectives were accomplished. The sky was clear for the daytime collection. Because of the late fall time frame, the sun elevation was below what is normally considered minimal for good MSS signal strength, and thus low contrast shows in some spectral regions.

Most of the flight lines were flown along site boundaries to accommodate the flight restrictions imposed by INEL facility safety considerations. This may not have placed the areas of most critical interest in the center of the image which is often considered the best position within the imagery for data analysis purposes. Additionally, the uniformly cold air, water, and ground, normal for this season, resulted in poor contrast between dry and wet soil. A few lines were repeated for better coverage.

In all, 33 flight lines were flown with a sun azimuth swing of about $-11^{\circ}$ to $+20^{\circ}$ relative to the flight heading and with sun elevations between $26^{\circ}$ and $29^{\circ}$ above the horizon. Refer to Appendix A, Multispectral Scanner and Photo Summary, for specific details concerning the areas of coverage.

The ground data collection was accomplished from a setup location at the RWMC site. Operating from their home along the Snake River, Richard and Kathy Rice (both EG\&G/Idaho) volunteered their time to collect the water temperature data. 


\subsection{Hanford Reservation}

The high-priority MSS and photo objectives were met; eighty percent of the secondary priority objectives were met, with varying quality. No unusual flight restrictions were imposed at Hanford, making it possible to adjust the flight lines to best center the hover points that were flown by the helicopter.

The daytime data were acquired over two consecutive days, neither of which was cloud free. High, thin clouds in varying amounts were present on both flight days; on no other days were conditions acceptable during the seven-day survey period. As at INEL, low sun elevation and uniformly low temperatures impacted the data quality.

Additional time was required to set up the MRS program and acquire the flight lines, which were greater in number and length than those at INEL. This resulted in sun azimuth changes larger than desirable. A tape drive failure created the need to repeat several flight lines. More than 60 flight lines were collected within sun azimuth swings between $-19^{\circ}$ and $+33^{\circ}$ and sun elevations between $18^{\circ}$ and $24^{\circ}$ above the horizon. Good predawn MSS data were collected over the river, but only on the two northern-most legs.

\section{AERIAL PHOTO ACQUISITION}

A Wild Leica RC-10 aerial mapping camera was used to acquire large-format (9-inch or 228mm) photographs for both sites and the surrounding area. A 6-inch $(153 \mathrm{~mm})$ lens was used with Aerocolor film for color photography. All photos were collected with 60 percent end-lap to facilitate stereoscopic viewing and sufficient side-lap to ensure contiguous coverage. Color photos were acquired simultaneously with the MSS data for all flight lines. These photos can be interpreted independently or in conjuction with the MSS imagery. The increased spatial resolution and stereoscopic viewing features complement the spectral content of digital MSS imagery.

\section{MSS AND AERIAL PHOTOGRAPHY DATA SUMMARIES}

A summary of the MSS data and photography collected at INEL and Hanford may be found in Appendix A. The index system used in the tables is based on a combination of several parameters. Each 
of the first four columns provides information needed to positively identify the data set. The first, second, and fourth columns are the date, time (military notation), and the target or site location. The third column lists the run and line number combination.

The run number is a sequential number advanced after each flight line by the scanner operator and imbedded into the data housekeeping. It normally begins at number 11 or 12 when starting a new tape. The next number will identify the blank period on the tape before the next flight line of data, hence the skipping of numbers in the sequence. Aborted or bad lines that are not listed in a final version of the data acquisition table will cause other numbers to be skipped. It is normal to have more than one "Run 11 " during a mission, as two or more HDDTs are typically used.

The line number is a reference to the MRS navigational system alignment. To set up the MRS program, it is necessary to first identify an axis or " 0 " flight line, the one from which all other parallel lines are referenced. The 0 line is selected prior to the survey and can be anywhere within, or outside of, the survey area, as long as it has the correct heading and two ground features which can be used as control or "hack" points.

All other parallel flight lines to be flown will become offsets to the 0 line. Normally, each incremental number from the 0 line represents 1,000 feet. Typically, a survey designed for complete coverage with multiple parallel flight lines would be set up so that the line spacing is equal to the altitude above ground. Therefore, if an altitude of 5,000 feet is desired (providing a nominal pixel resolution of 12.5 feet), a line spacing of 5,000 feet is selected. The line numbers would then increase incrementally by 5 , (i.e. $-5,0,+5$, +10 , etc.). Therefore, a -5 line will be offset 5,000 feet to one side of the 0 line, and a +10 will be offset line on the opposite side of the axis line by 10,000 feet.

The run/line number combination is only applicable when the scanner and the MRS are both used. A scanner line flown without benefit of the MRS would show a run number only, or a run number combined with "vis" for a flight line that was visually navigated. The MRS may be used without the MSS for photo collection. In this case there will be no run number, just as with line number. A run number and line number combination will possibly be repeated, making it necessary to use the date and/or time to differentiate between the two data sets. Often, more than one 0 line will also be set up for a mission, making the target or location name a necessary part of the identifier. To understand where the flight lines are located, a map is necessary with at least the 0 line(s) and the \pm offset direction identified. 


\section{MSS DATA PROCESSING}

\subsection{Data Decommutation}

MSS data recorded on the HDDT must be decommutated prior to digital image processing. Decommutation is the conversion of an analog, serial, bit data stream to a digital format that is readable by computer. The data are decommutated from HDDT format into a computer-compatible format. The data are quality checked and then archived to optical disk. The output raw byte data can be provided on several different types of media. Currently, supported media include $8 \mathrm{~mm}$ tape, 9-track tape, and 5 1/4-inch optical disk. A variety of standard image processing system file formats are also available.

\subsection{Geometric Correction}

Prior to analysis, the decommutated data are typically corrected for systematic geometric distortions. The data are processed to minimize the tangential distortion (s-bend) inherent in electro-optical scanner data, and to compensate for any overscan based on the velocity/height ratio. ${ }^{1}$ In this instance, the data collected for the INEL survey have not been geometrically corrected while the data collected for the Hanford survey have been corrected.

\subsection{Radiometric Correction}

The channels containing thermal infrared data (channels 11 and 12) were radiometrically corrected, based on the recorded temperatures of the two internal reference blackbodies. This correction is necessary when the relative temperature difference between two features (within a scene) is required. The temperature difference is nominally accurate to within one tenth of a degree centigrade. However, to obtain the absolute temperature of any feature, additional information about atmospheric conditions and the emissivity characteristics of the feature must be known. This usually involves on-site ground temperature measurements during the data acquisition. As noted before, the data for INEL have not been radiometrically corrected while the data for Hanford have been. 


\section{MSS IMAGE ENHANCEMENT}

The raw data produced by the MSS inherently contain a great deal of information. Because these data are in digital format, the value of this information can be greatly increased by the use of digital image processing. Interactive digital image analyses were performed using Hewlett Packard workstations and the EASI-PACE Image Processing system developed by PCI, Ontario, Canada. Effective image processing techniques can range from very simple, straight-forward enhancements to complicated, iterative processing algorithms.

The airborne multispectral scanners operated by the RSL offer many advantages over traditional aerial photography and commercial remote sensing satellites. The scanners collect data at wavelengths beyond the range of conventional aerial photography. In addition to the visible and near infrared wavelengths acquired by aerial photography, the MSS collects data also in the near ultraviolet, middle infrared, and thermal infrared portions of the electromagnetic spectrum. By flying at lower altitudes, the scanners collect data at much greater spatial resolution than that available from commercial satellites. An airborne MSS combines many of the advantages of aerial photography and commercial remote sensing satellites.

\subsection{Background Phenomenology}

Since the MSS collects surface reflectance data in the visible and reflective infrared, the feature of interest must be on the surface to be detected. However, surficial anomalies can point to the presence or absence of a sub-surface phenomenon. Two useful applications of MSS data are the detection of seeps and soil disturbances.

Seeps are formed when water percolating through the soil profile encounters a less permeable or impervious layer. ${ }^{2}$ The water follows the contour of this layer and "seeps" out along hillsides or other areas where the layer reaches the surface. Open water and saturated soils are common in seeps and springs. A potential exists for contaminants to be transported in this manner.

Typically, seeps and springs are characterized by a vigorous hydrophyte community which develops because of the higher soil moisture regime. While this is true for a non-arid location, the areas surveyed at INEL and Hanford are in a semi-arid environment where water that rises to the surface is immediately evaporated. As a result, the vegetation growth pattern may be enhanced but is not as distinguishable as 
in a less arid environment. In this case, however, MSS imagery may still be useful to map vegetation location and surface water transport patterns.

The detection of soil disturbances with visible, reflective infrared, and thermal infrared energy depends on many surface and subsurface characteristics. These factors interact and change in relative importance making the net spectral effect difficult to predict. In addition, the potential range of disturbances to background make it difficult to predict discrimination. Fortunately, the arid climate and sparse vegetation patterns at INEL and Hanford allow for some valid assumptions to be made.

The act of burying an object or material typically involves clearing any vegetation cover, removing some soil, placement of the object or material, and replacing the soil. Since this process is normally accomplished by scraping the earth over the top of the site, areas that have been scraped and are clear of vegetation are often readily apparent.

The most obvious types of soil disturbances occur when the bare soil has been exposed, i.e. the vegetation cover has been removed. Many soils are vertically stratified and the mixing of soils by digging will change their surface appearance (color, moisture content, composition, and texture). This definitely modifies the observed spectral reflectance of the soil. The disturbance of homogeneous soils will also affect the geometry of the surface. Rough soils are generally darker than smooth soils and directional reflectance differences will be larger. Some differences that are not apparent on aerial photography or to the naked eye will become readily apparent in MSS imagery.

Even the most arid areas usually have some vegetation that will be affected by the burial of an object. Soil removal may result in vegetation stress, or conversely, may improve vegetation growth by aerating the soil and/or changing drainage and soil moisture conditions. In either case, MSS sensing techniques have been developed that will often detect these changes.

As indicated by this brief review of pertinent factors, man-made disturbances to the soil regime can affect the soil and vegetation cover in many ways. This can result in various spectral response changes to the soil disturbance. These anomalies can be remotely sensed with multispectral scanners and enhanced by digital image processing techniques.

\subsection{Contrast Enhancements}

When a digital image is created, the quantizing process defines a discrete range of values often termed gray or brightness levels. For a typical Daedalus AADS1268 digital image, the available brightness 
levels range from 0 (black, or no signal available) to 255 (white, maximum signal). The apparent contrast (or relative difference in brightness values between scene features) can be improved with digital contrast enhancement. This is especially effective over a desert area such as that at INEL. Contrast enhancement takes the narrow range of the raw data and stretches it to cover the full potential range of the data. ${ }^{3}$ Subtle differences in tone between different features on the ground are thus emphasized, and become much more visually apparent. All of the examples shown in the following sections have been contrast enhanced.

\subsection{Color Composites}

The visual perception of color is usually more acute than for shades of gray. A standard color composite image is a three-channel combination of different MSS channels, providing a visual, color display of the imagery. This display can be in either the form of an image on a computer monitor, or exposed and converted into a film product. A computer monitor uses three color signals to create an image on the screen; by placing a different MSS channel on each signal, a composite image of the three channels is created. With film products, each of the three film layers can be used to display a different MSS channel, again resulting in a composite image. The color of features in a standard composite image is a function of relative reflectance differences in the spectral channels selected for the composite.

Any three MSS channels, including the thermal channel, can be used to produce a color composite. The best approach is to select a channel combination that produces the optimal color separation between the features of interest and the background. Several techniques have been developed to facilitate channel set selection.

\subsection{Principal Components}

Principal component analysis is commonly used as a data dimensionality reduction technique for large MSS data sets in which there may be significant correlation between MSS channels. ${ }^{4}$ The first principal component is a linear transformation selected to account for the largest proportion of the variation in the total data set. Subsequent orthogonal components are selected such that they account for the largest proportion of the residual variance. The respective transformations are defined by the calculated eigenvectors and ranked by the magnitude of the corresponding eigenvalues. For these data sets, the principal 
component analysis was performed using only the ten visible and reflective infrared channels (MSS channels 1-10). The thermal channels were excluded because thermal response is very dynamic and differs from survey to survey.

\subsection{Geologic Ratio Enhancement}

Another useful image enhancement for sparsely vegetated areas such as INEL and the Hanford Reservation is commonly referred to as a geologic ratio enhancement. This enhancement brings out subtle differences in mineral types as various hues on the resultant image. It is accomplished by ratioing the appropriate MSS channels. The enhancement was implemented by: 1) dividing channel 9 by channel 10 and putting the result in the red signal, 2) dividing channel 9 by channel 7 and putting the result in the green signal, and 3) dividing channel 5 by channel 2 and putting the result in the blue signal. As mentioned previously, all three were then contrast stretched to enhance subtle details.

\section{IMAGE ANALYSIS}

The previously mentioned techniques were applied to selected areas of the MSS data to look for signs of soil disturbance and water transport. Various channel combinations were displayed on the monitor and selected contrast stretches were applied as appropriate. Several sample images were prepared and are presented in Figures 4 through 12.

\subsection{INEL Imagery}

The data presented in Figure 4 are from the two flight lines covering the Idaho Chemical Processing Plant (ICPP). The figure consists of three pairs of the two flight lines, each pair enhanced differently.

The left pair of flight lines represents an "optimal” MSS channel set selection consisting of MSS channels 10,7, and 9 as red, green, and blue, respectively. Areas of soil disturbance are shown as various shades of green. Indications of surface runoff are evidenced by the "spider web" of stream beds at the top of each image. 


\section{INEL \\ ICPP AREA}
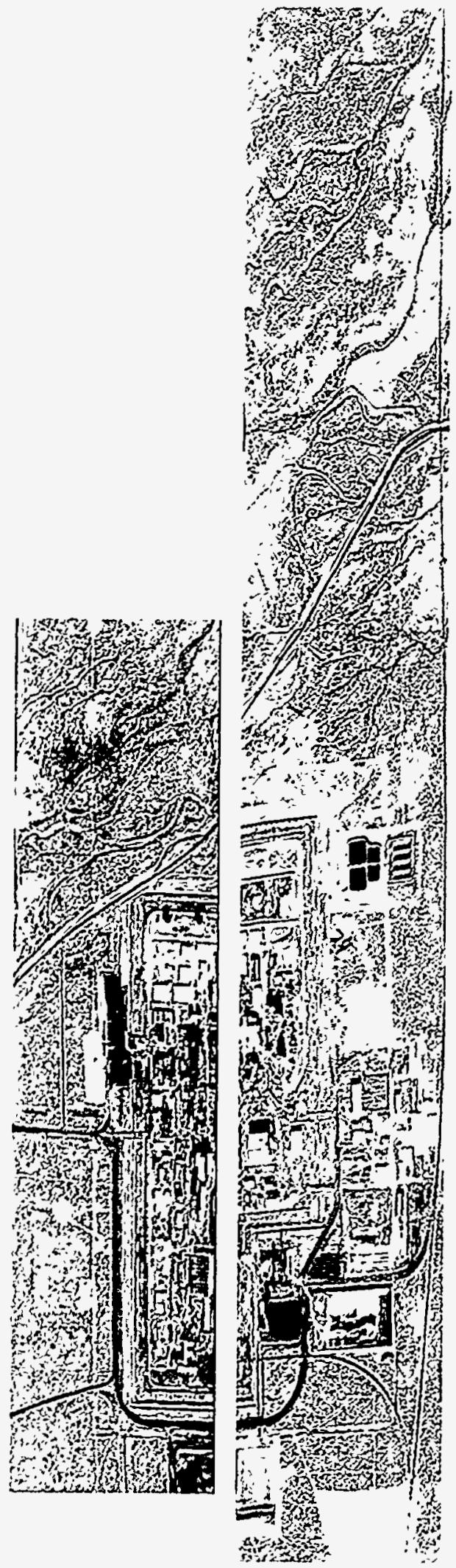
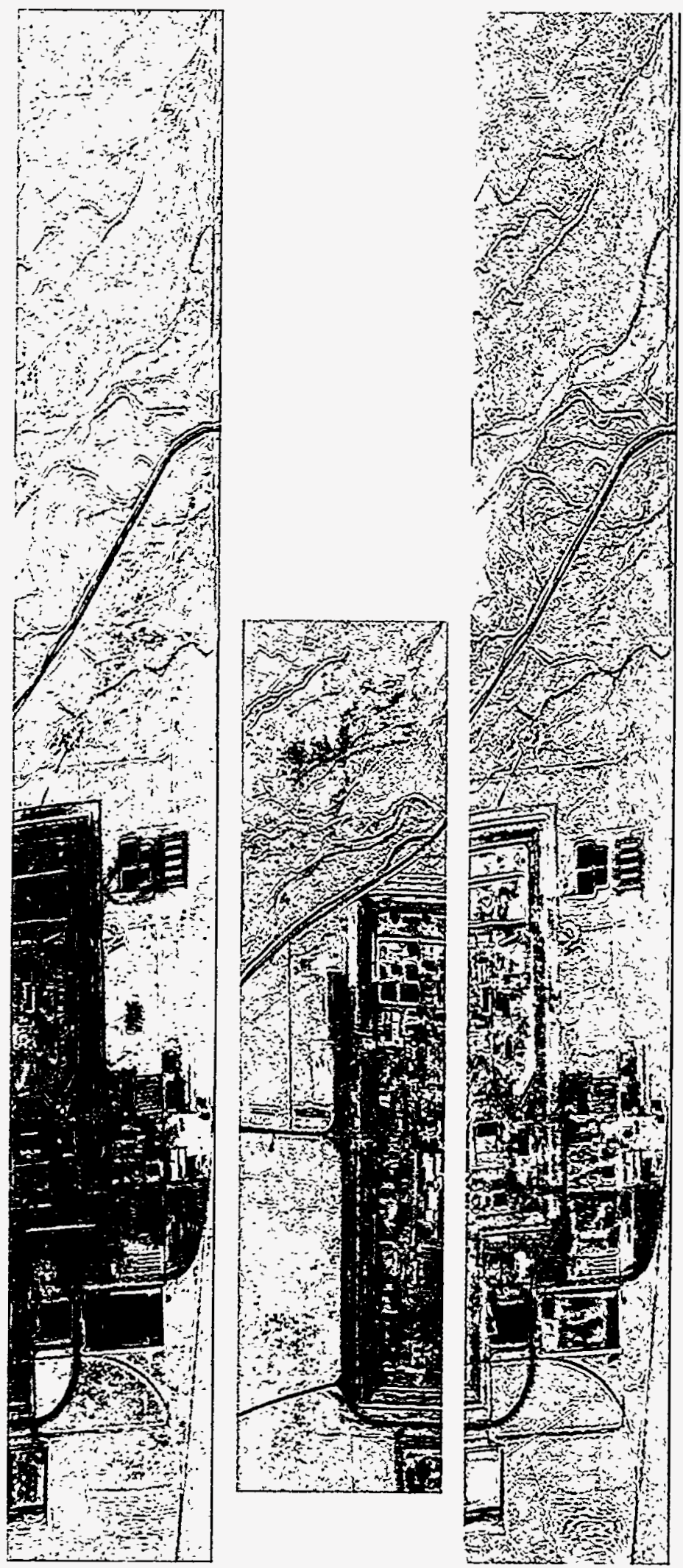

SIGIS \#94215.06 


\section{INEL RWMC AREA}
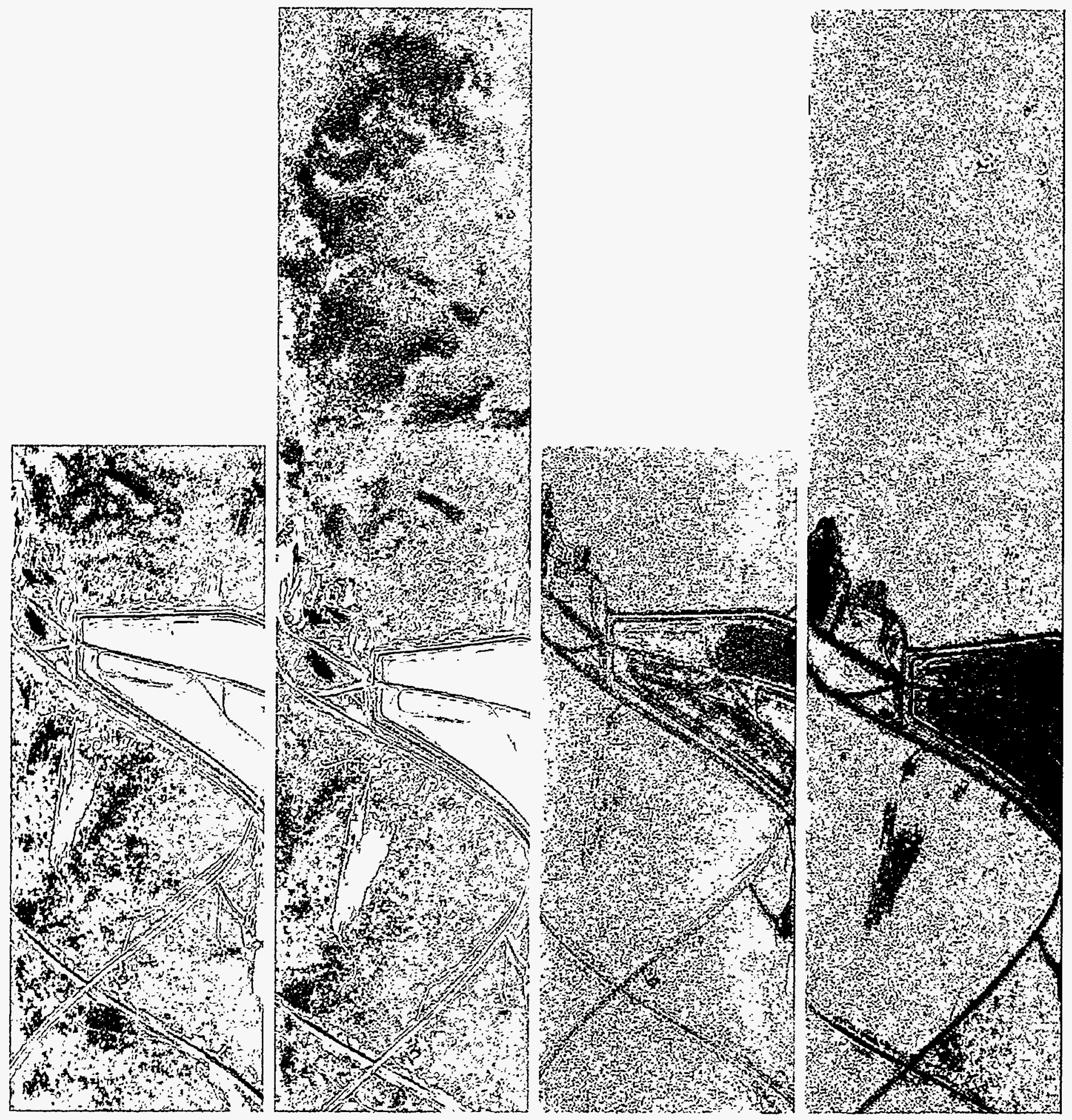


\section{HANFORD \\ TRAIN DECONTAMINATION AREA}

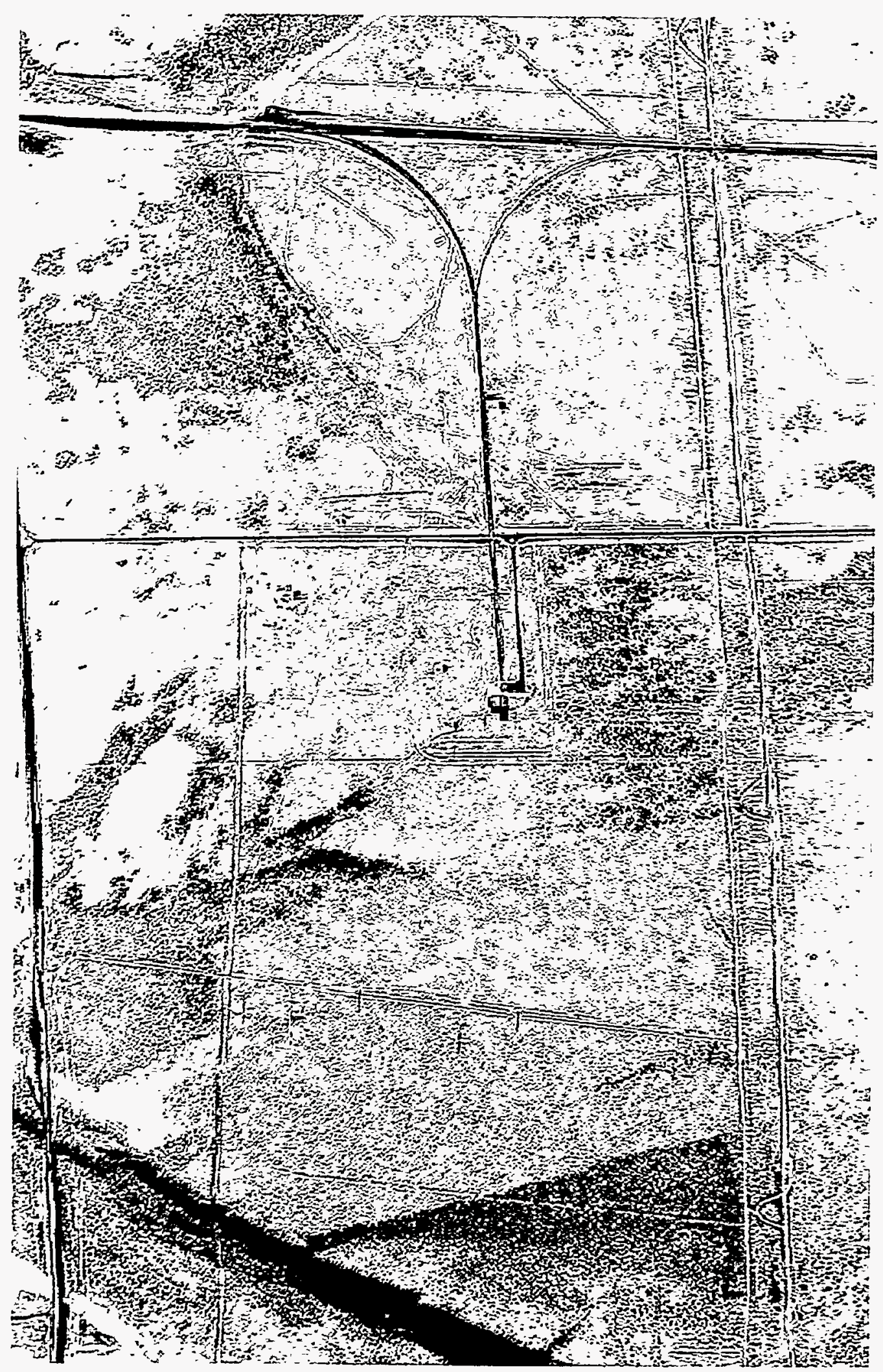

SIGIS \#94215.08 


\section{HANFORD - 200 EAST COLOR SIMULATION/THERMAL MOSAIC}
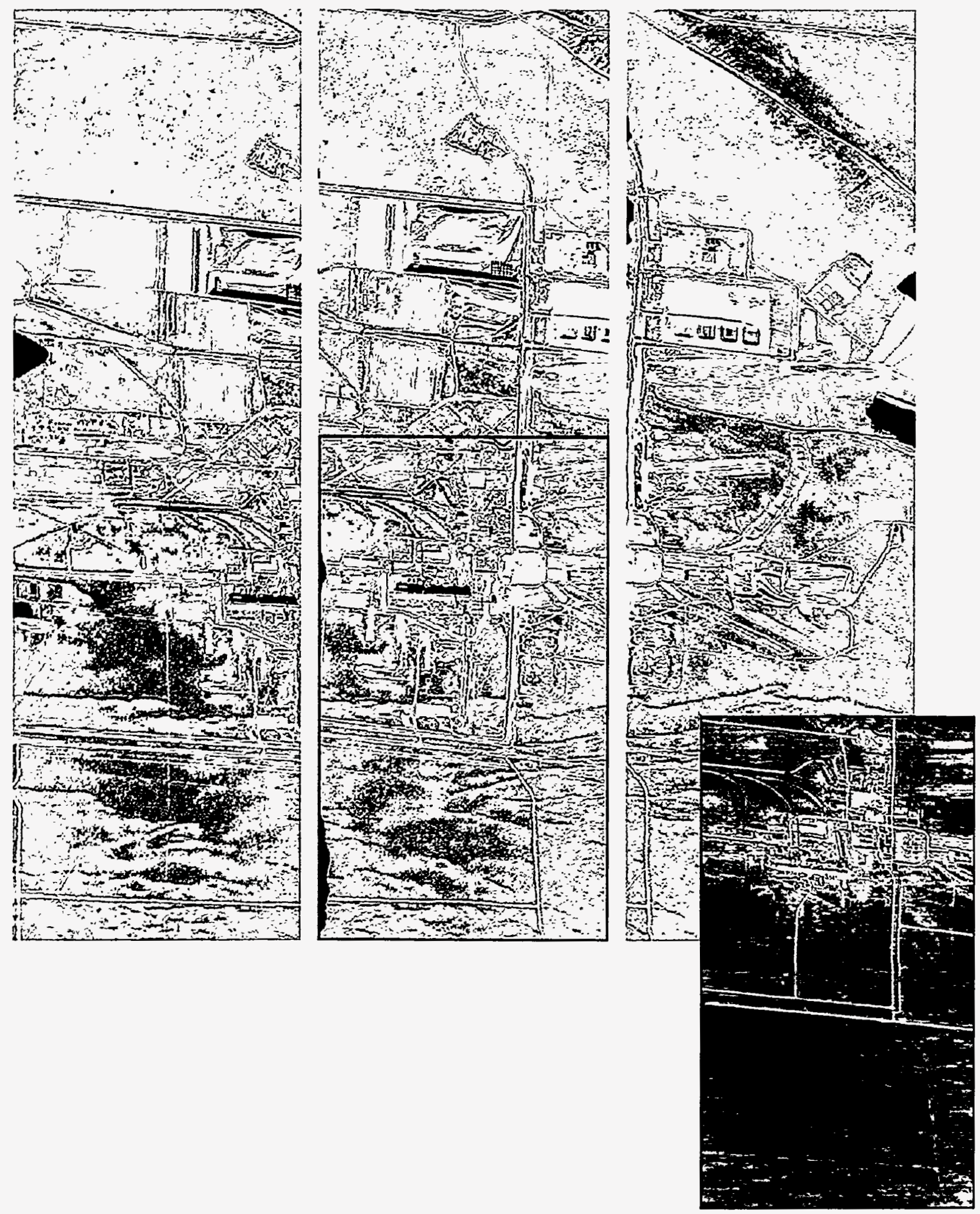

SIGIS \#94215.09 


\section{INEL-ICPP AREA \\ "DISTURBED EARTH" ENHANCEMENT}
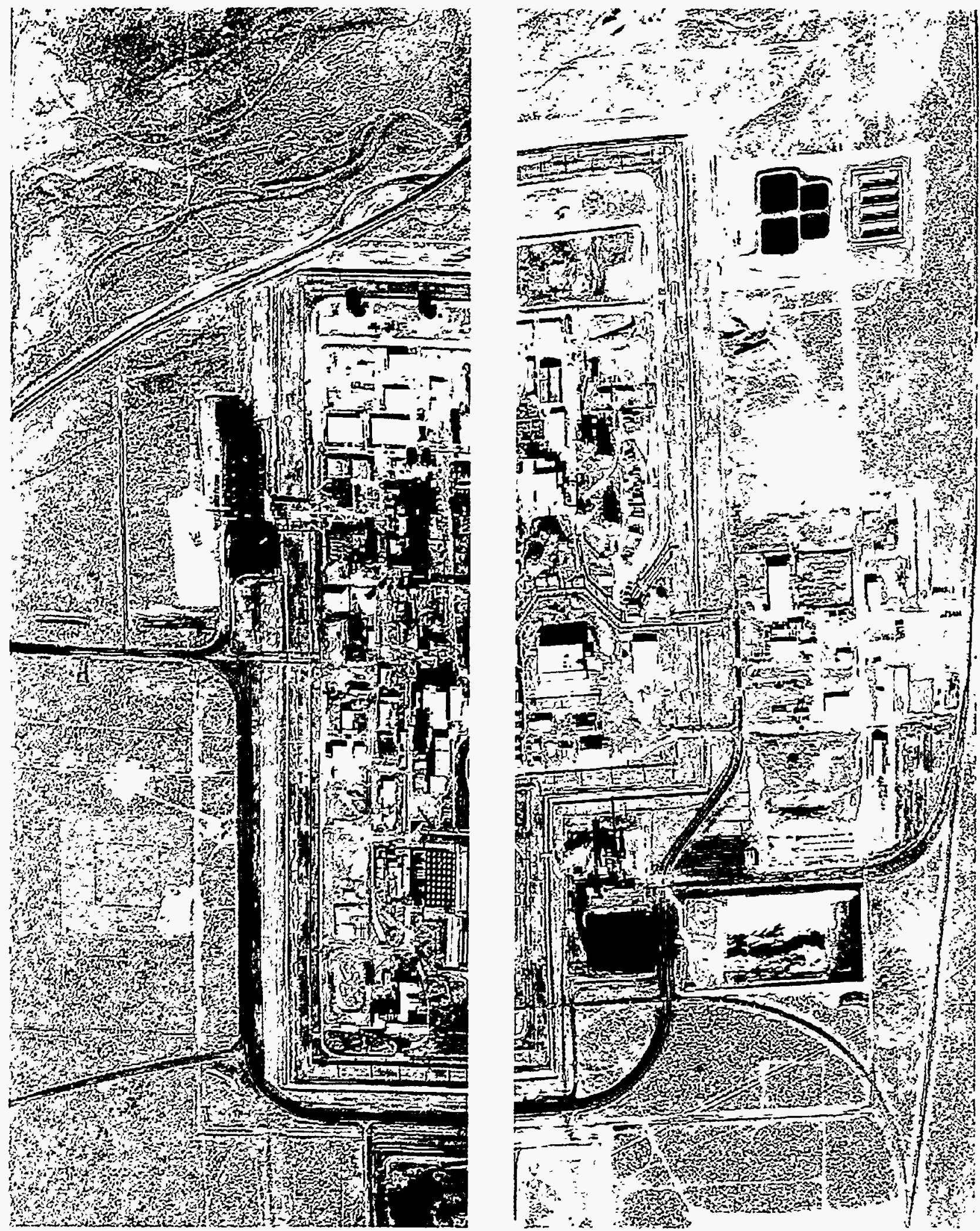

SIGIS \#9421501 


\section{INEL-ICPP AREA}

\section{PRINCIPAL COMPONENTS}
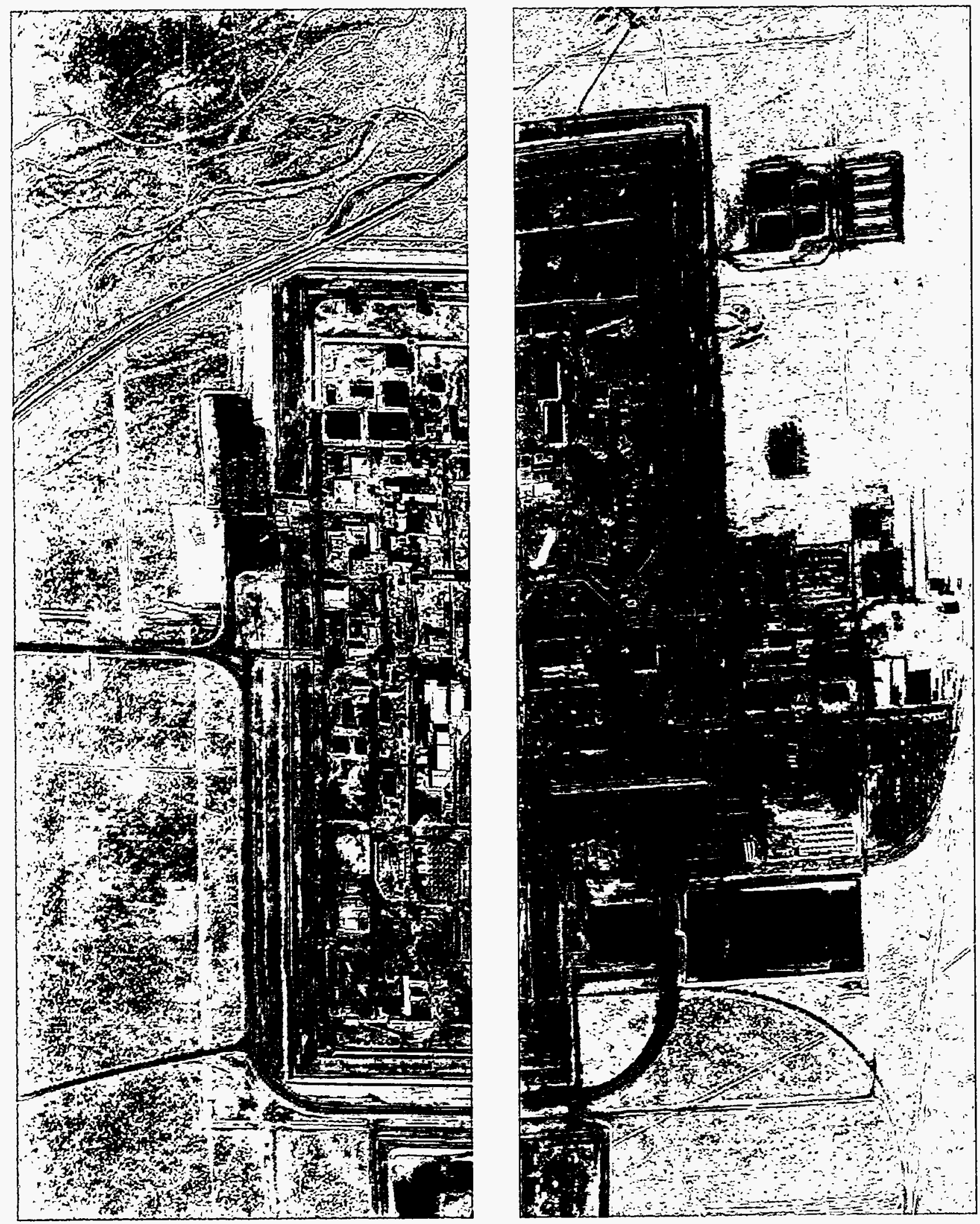

SIGIS $\$ 9421502$ 


\section{INEL-ICPP AREA}

\section{THERMAL COMPOSITE}
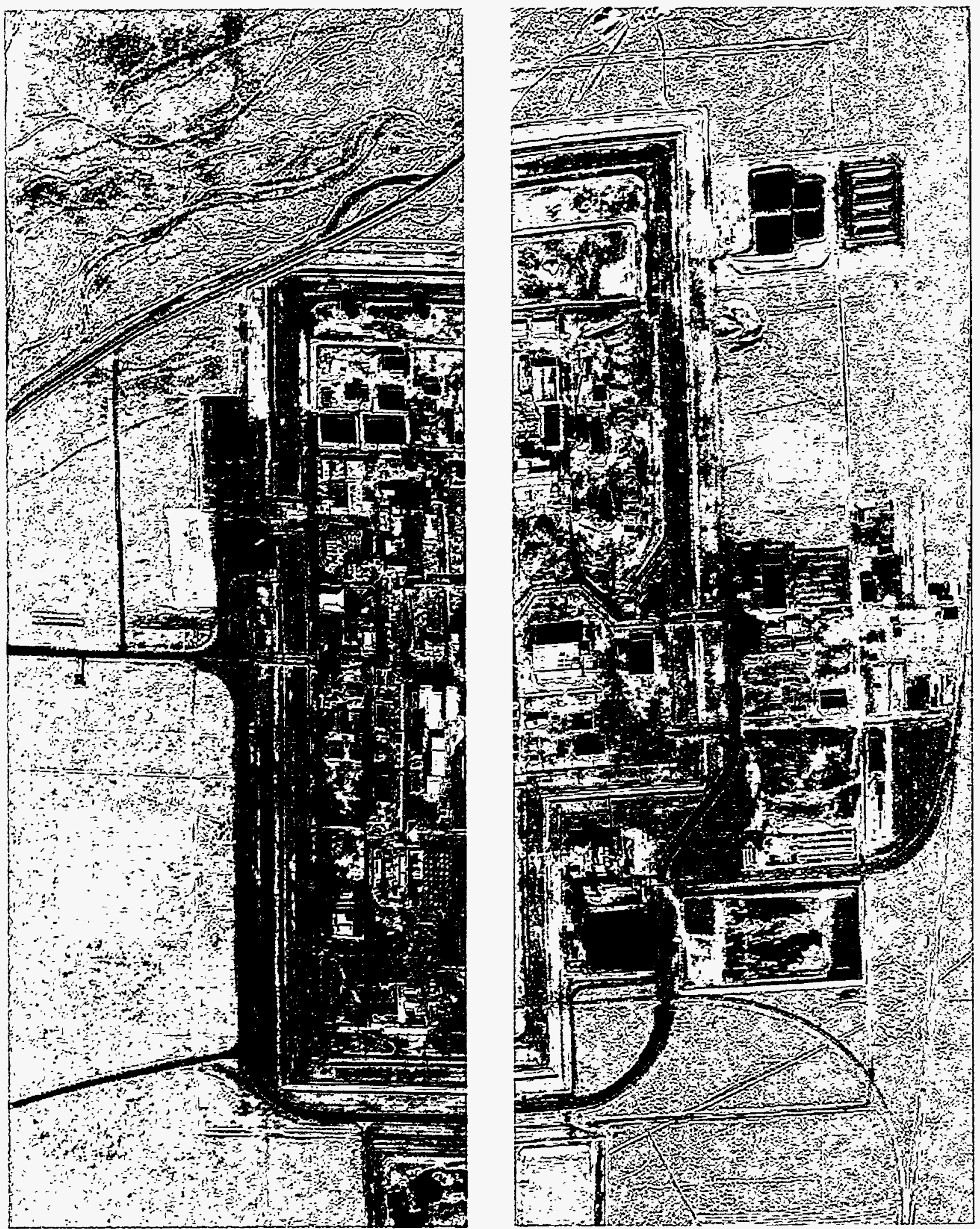


\section{INEL-RWMC \\ "DISTURBED EARTH" ENHANCEMENT}

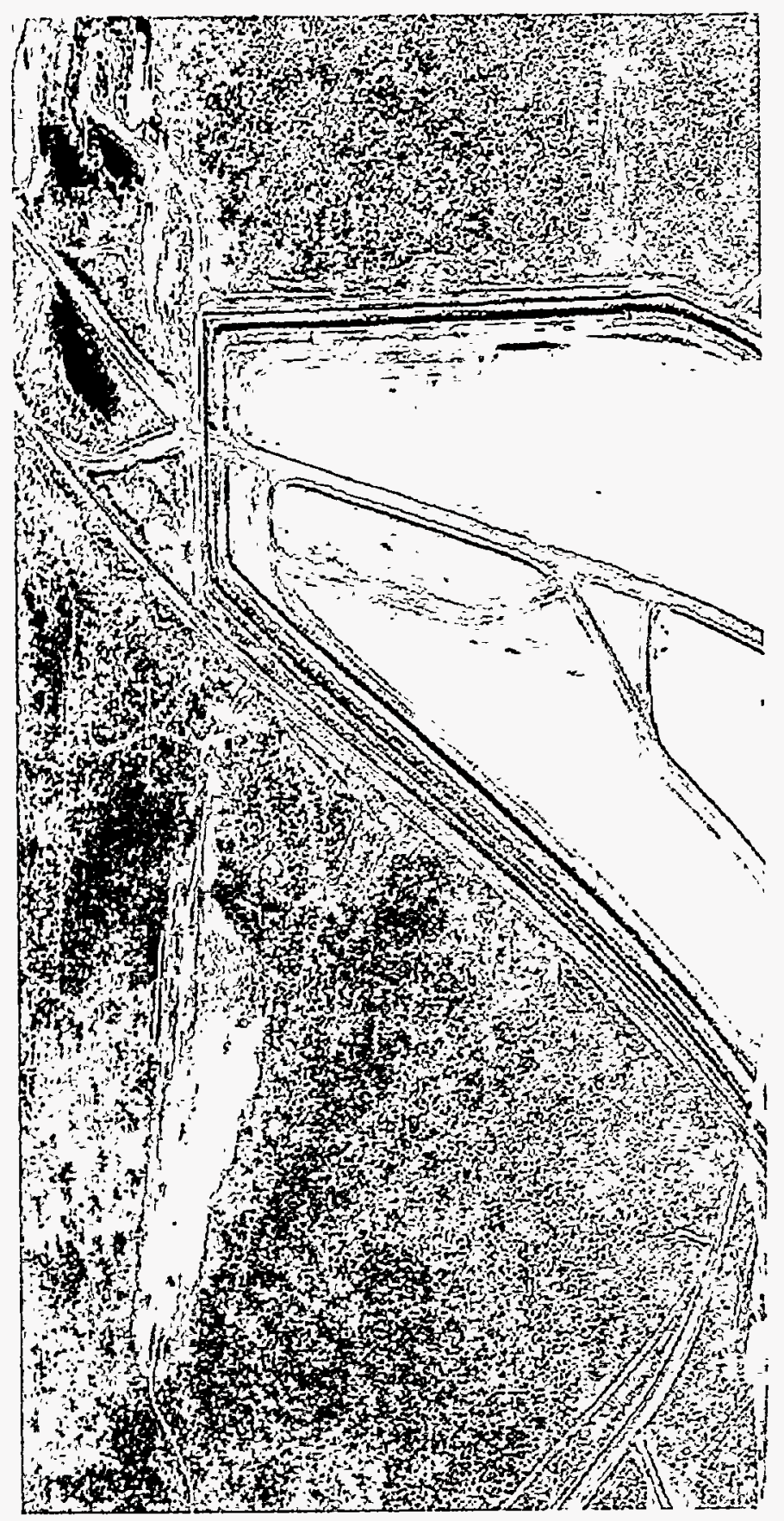

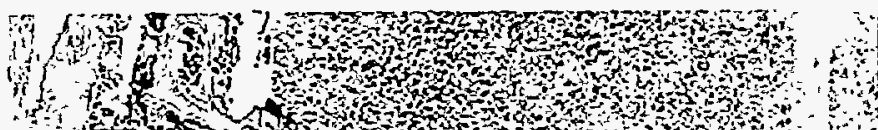

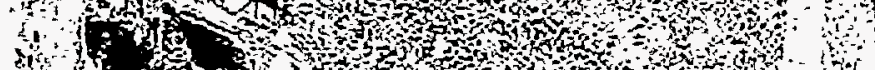

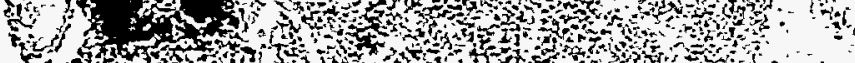

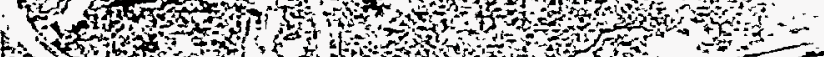

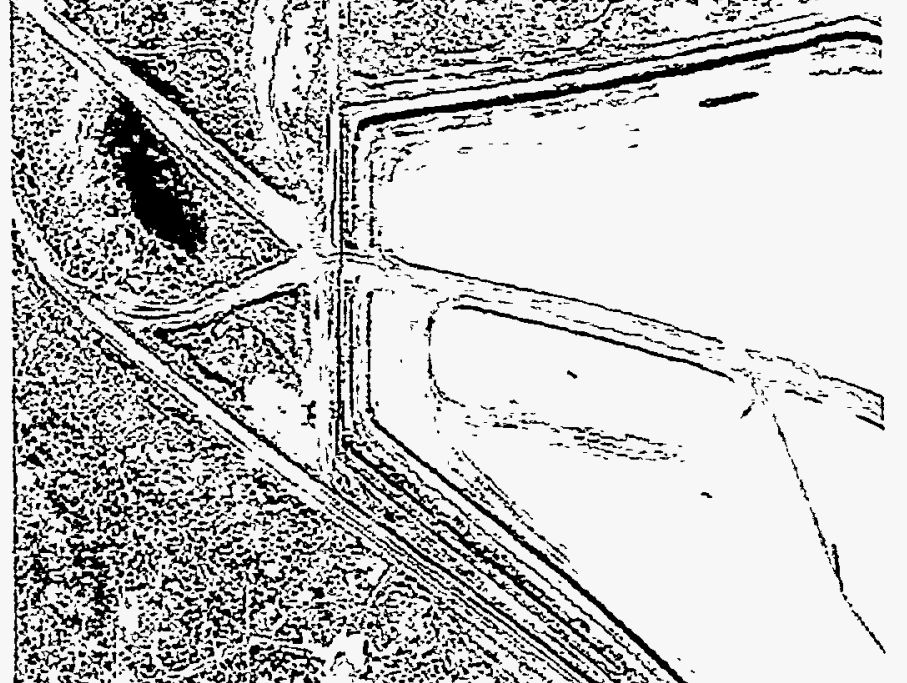

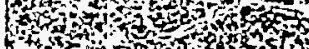
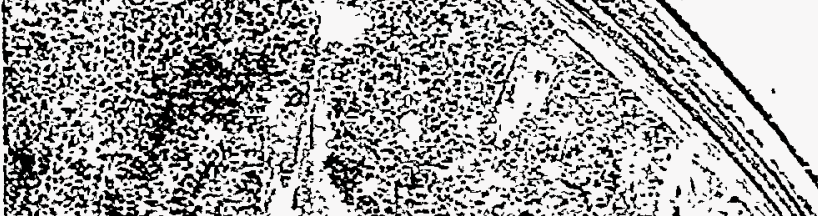

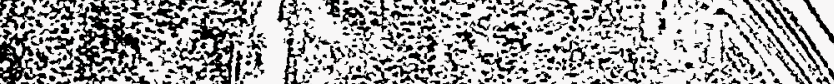

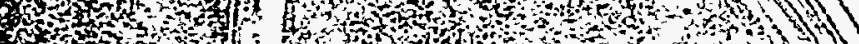
Hot mon

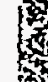

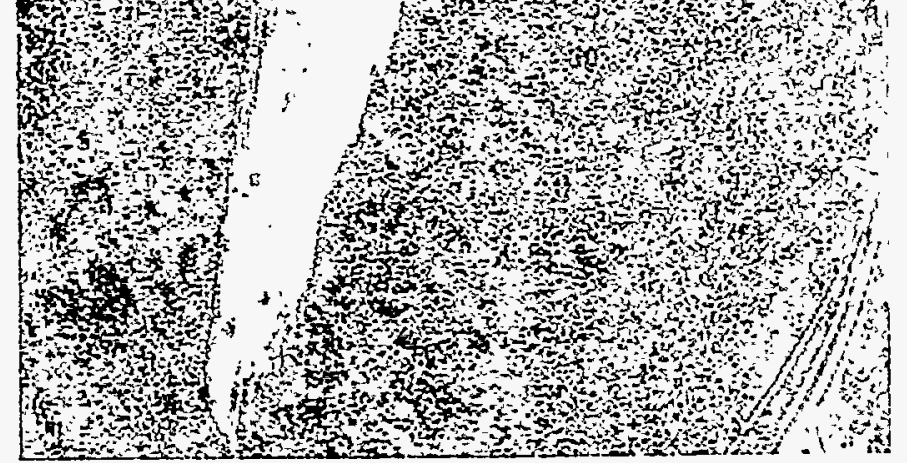




\section{INEL-RWMC \\ GEOLOGIC ENHANCEMENT}
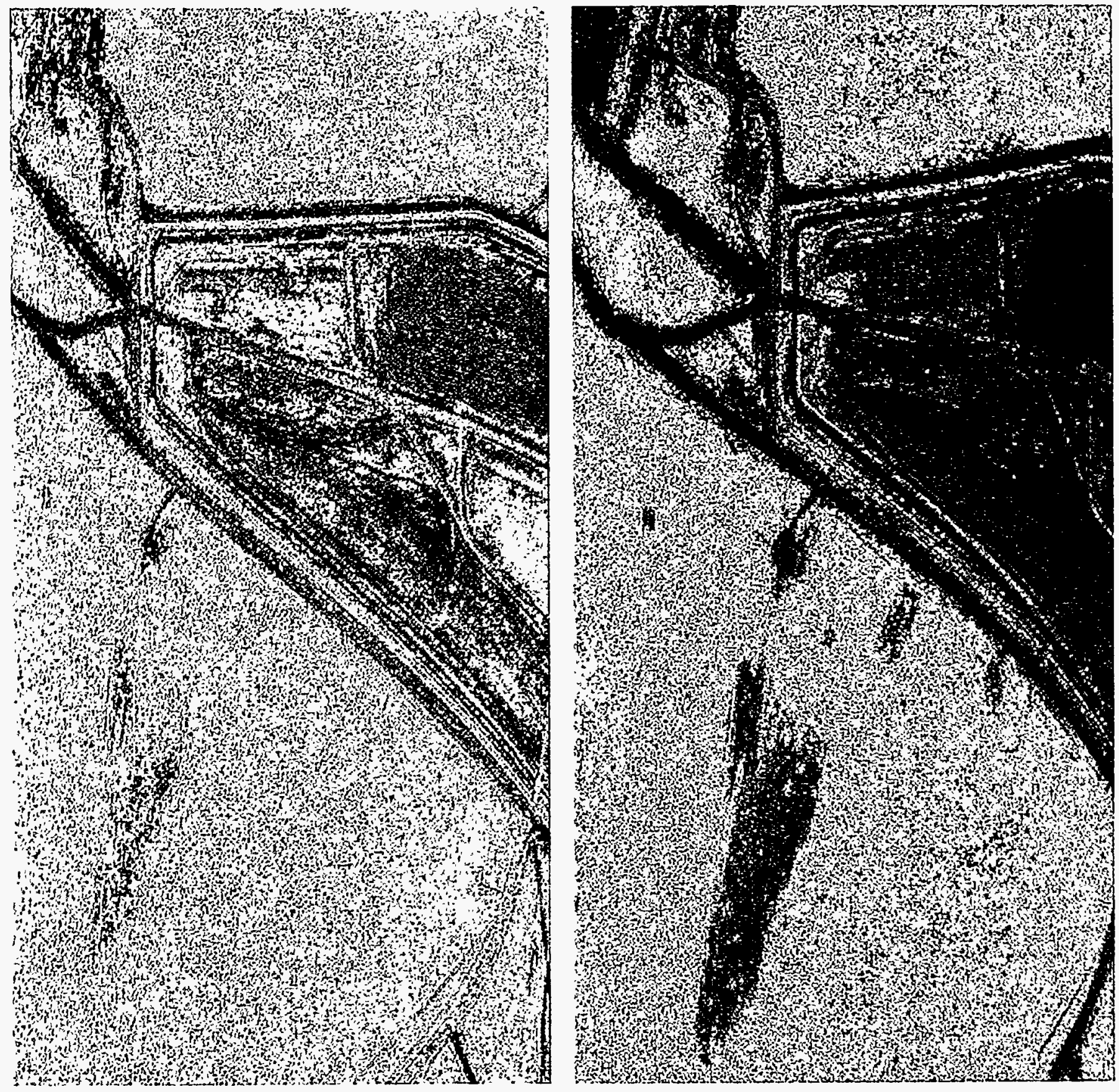

SIGIS \#91215 05, 
The middle pair of flight lines represents the first three principal components as red, green, and blue, respectively. An examination of the correlation matrix reveals that the first channel is indicative of the overall "brightness" of the data while the second channel represents the vegetation content of the image.

The right pair of flight lines represents a thermal composite consisting of MSS channels 11, 9, and 7 as red, green, and blue, respectively. The thermally warmest areas appear red in this composite and are primarily man-made features (roads and buildings). The two water bodies near the center of the image are cool, resulting in a near black response. There appears to be some water in the stream bed at the top of the image but no evidence of water in the rest of the image.

The data presented in Figure 5 are from the two flight lines that cover the Radiation Waste Management Center (RWMC) at INEL. The figure consists of two pairs of flight lines with different enhancements.

The left pair is a disturbance enhancement, as mentioned above. Again, the disturbed areas are shown in shades of green. The area surrounding the open pit and the access roads are highlighted in this enhancement.

The right pair of flight lines is the geologic enhancement, described earlier. In this instance, the disturbed areas are shades of purple through dark blue. Most of the yellow coloration is an artifact of differential sun angle illumination (note its movement from the right side to left side for the different flight headings). This effect could be greatly minimized or possibly eliminated through additional processing.

Figures 9 through 12 are enlargements of the areas of interest from Figures 4 and 5, presented for easier image preview and analysis.

\subsection{Hanford Imagery}

The data presented in Figure 6 are from the flight line covering the train decontamination area at Hanford. This flight line consists of an "optimal" MSS channel selection. A target and background were selected to discriminate between soil-disturbed areas and normal surface features. The MSS channel selection for this figure is 10,7 , and 2 as red, green, and blue, respectively. The soil-disturbed areas appear in various shades of blue, with the normal background surface features shown in shades of red. Green shades in the image represent vegetation. 
The data presented in Figure 7 are from flight lines covering the 200 East area at Hanford. Figure 7 is a color simulation which consists of channels 5, 3, and 2 as red, green, and blue, respectively. This graphic illustrates the dry conditions in which the MSS data were acquired. The overall light brown appearance of the ground suggests very little to no live vegetation with minimum to no surface moisture.

To further indicate these dry conditions, the black and white subset image is predawn thermal data of the same site. The bright returns (white features) in the thermal subset image are primarily man-made features such as rooftops, piping, and roads. The light gray to darker returns (cooler) are mostly natural surface consisting of dried out vegetation and dry soil. No bright returns in the natural surface areas strongly suggest that no moisture was present in these areas during data acquisition.

\section{CONCLUSIONS AND RECOMMENDATIONS}

An airborne MSS survey of selected sites on the Idaho National Engineering Laboratory and the Hanford Reservation was performed in mid-November 1993. The data acquisition involved relatively low sun elevations and very dry soil conditions. The primary objectives of the survey were completed. Aerial MSS and photography were acquired; sample images were prepared and are included in this mission summary report.

To illustrate two potential applications, the MSS data were digitally enhanced to facilitate the detection of soil disturbance and evidence of surface water transport. The main conclusion of this study was that MSS data acquired under these conditions can be useful for soil disturbance detection. The imagery did not prove very useful, however, for direct indications of surface water transport. It was possible to infer some water transport patterns from dry water beds, but only if surface indications were present. The low utility of the thermal infrared imagery for this application was not fully anticipated. The dry conditions prior to and during the acquisition period apparently hindered this type of assessment.

The survey should be performed with the sun at a higher elevation and with greater soil moisture. For both locations, the relatively rainy months of spring and early summer would be better. Under conditions of higher soil moisture, thermal infrared signatures of potential water transport should provide better results. 
The MSS data and aerial photographs of the INEL and Hanford Reservation are archived at the Remote Sensing Laboratory in Las Vegas, Nevada. Requests for the data and/or analysis assistance should be directed to the Department of Energy, Nevada Operations Office (DOE/NV). 


\section{MULTISPECTRAL SCANNER AND PHOTO SUMMARY}

\begin{tabular}{|c|c|c|c|c|c|c|c|c|c|}
\hline \multicolumn{10}{|c|}{$\begin{array}{c}\text { INEL Multispectral Scanner and Photo Summary } \\
\text { Daytime Coverage, November 11, } 1993 \\
\text { Daedalus AADS1268 Multispectral Scanner } \\
\text { Wild Heerbrugg RC-10 Aerial Mapping Camera }\end{array}$} \\
\hline Date & Time & Run & Line/Target & AGL & $\begin{array}{l}\text { True } \\
\text { Head }\end{array}$ & Perf \# & Frames & Scale & Comments \\
\hline $11 / 11 / 93$ & 1136 & 31 & Reflectance targets & $1,300^{\prime}$ & $001^{\circ}$ & 7614 & $01-07$ & $1: 2,600$ & Ch 12 saturated \\
\hline $11 / 11 / 93$ & 1141 & 33 & RWMC & $1,300^{\prime}$ & $356^{\circ}$ & 7614 & $08-12$ & $1: 2,600$ & Ch 12 saturated \\
\hline $11 / 11 / 93$ & 1147 & 35 & ICPP (east) & $1,300^{\prime}$ & $004^{\circ}$ & 7614 & $14-1$ & $1: 2,600$ & \\
\hline $11 / 11 / 93$ & 1152 & 37 & ICPP (west) & $1,300^{\prime}$ & $179^{\circ}$ & 7614 & $22-33$ & $1: 2,600$ & \\
\hline $11 / 11 / 93$ & 1156 & 39 & ICPP (east) & $1,300^{\prime}$ & $001^{\circ}$ & 7614 & $34-52$ & $1: 2,600$ & Repeat \\
\hline $11 / 11 / 93$ & 1203 & 41 & Borax-1 & $1,300^{\prime}$ & $360^{\circ}$ & 7614 & $54-57$ & $1: 2,600$ & \\
\hline $11 / 11 / 93$ & 1207 & 43 & Borax-1 & $1,300^{\prime}$ & $180^{\circ}$ & 7614 & $57-61$ & $1: 2,600$ & Repeat \\
\hline $11 / 11 / 93$ & 1214 & 45 & TRA (east) & $1,300^{\prime}$ & $002^{\circ}$ & 7614 & $63-72$ & $1: 2,600$ & \\
\hline $11 / 11 / 93$ & 1217 & 47 & TRA (west) & $1,300^{\prime}$ & $180^{\circ}$ & 7614 & $73-85$ & $1: 2,600$ & \\
\hline $11 / 11 / 93$ & 1223 & 49 & SL-1 & $1,300^{\prime}$ & $346^{\circ}$ & - & - & - & Abort \\
\hline $11 / 11 / 93$ & 1229 & 51 & SL-1 & $1,300^{\prime}$ & $001^{\circ}$ & 7614 & $89-93$ & $1: 2,600$ & \\
\hline $11 / 11 / 93$ & 1234 & 53 & Reflectance targets & $1,300^{\prime}$ & $003^{\circ}$ & 7614 & $97-105$ & $1: 2,600$ & \\
\hline $11 / 11 / 93$ & 1239 & 55 & RWMC & $1,300^{\prime}$ & $356^{\circ}$ & 7614 & $106-111$ & $1: 2,600$ & Ch 12 saturated \\
\hline $11 / 11 / 93$ & 1247 & 57 & RWMC & $1,300^{\prime}$ & $173^{\circ}$ & 7614 & $112-116$ & $1: 2,600$ & Ch 12 saturated \\
\hline $11 / 11 / 93$ & 1300 & 59 & River site & $1,300^{\prime}$ & $216^{\circ}$ & 7614 & $119-122$ & $1: 2,600$ & \\
\hline $11 / 11 / 93$ & 1310 & 61 & ICPP & $7,000^{\prime}$ & $269^{\circ}$ & 7614 & $123-125$ & $1: 14,000$ & Sun off right wing \\
\hline $11 / 11 / 93$ & 1315 & 63 & TRA & $7,000^{\prime}$ & $089^{\circ}$ & 7614 & $126-128$ & $1: 4,000$ & Frame 127 center \\
\hline $11 / 11 / 93$ & 1321 & 65 & ICPP & $7,000^{\prime}$ & $177^{\circ}$ & 7614 & $129-131$ & $1: 4,000$ & Frame 130 center \\
\hline $11 / 11 / 93$ & 1326 & 67 & RWMC & $7,000^{\prime}$ & $270^{\circ}$ & 7614 & $133-137$ & $1: 4,000$ & \\
\hline $11 / 11 / 93$ & 1342 & 02 & Airport & $5,000^{\circ}$ & $218^{\circ}$ & - & - & $1: 10,000$ & Too low \\
\hline $11 / 11 / 93$ & 1347 & 03 & Airport & $10,000^{\circ}$ & $218^{\circ}$ & 7614 & $147-150$ & $1: 20,000$ & Frame 148 center \\
\hline
\end{tabular}

Note: Headings have been adjusted by $+16^{\circ}$ in this summary to read "true"; logs read "magnetic." 


\begin{tabular}{|c|c|c|l|l|l|l|l|l|l|}
\hline \multicolumn{7}{|c|}{ INEL Multispectral Scanner and Photo Summary } \\
Nighttime Coverage, November 12, 1993 \\
Daedalus AADS1268 Multispectral Scanner \\
Wild Heerbrugg RC-10 Aerial Mapping Camera \\
\hline Date & Time & Run & Line/Target & AGL & $\begin{array}{c}\text { True } \\
\text { Head }\end{array}$ & Perf \# & Frames & Scale & Comments \\
\hline $11 / 12 / 93$ & 0640 & 10 & ICPP & $1,300^{\prime}$ & $182^{\circ}$ & - & - & - & No MSS data \\
$11 / 12 / 93$ & 0655 & 11 & ICPP (east) & $1,300^{\prime}$ & $358^{\circ}$ & - & - & - & \\
$11 / 12 / 93$ & 0658 & 13 & ICPP (west) & $1,300^{\prime}$ & $179^{\circ}$ & - & - & - & \\
$11 / 12 / 93$ & 0701 & 15 & Borax-1 & $1,300^{\prime}$ & $359^{\circ}$ & - & - & - & Off target \\
$11 / 12 / 93$ & 0704 & 17 & TRA (west) & $1,300^{\prime}$ & $358^{\circ}$ & - & - & - & \\
$11 / 12 / 93$ & 0708 & 20 & TRA (east) & $1,300^{\prime}$ & $180^{\circ}$ & - & - & - & \\
$11 / 12 / 93$ & 0711 & 23 & RWMC (east) & $1,300^{\prime}$ & $176^{\circ}$ & - & - & - & \\
$11 / 12 / 93$ & 0714 & 25 & RWMC (west) & $1,300^{\prime}$ & $356^{\circ}$ & - & - & - & \\
$11 / 12 / 93$ & 0716 & 27 & RWMC (west) & $1,300^{\prime}$ & $177^{\circ}$ & - & - & - & \\
$11 / 12 / 93$ & 0720 & 29 & Borax-1 & $1,300^{\prime}$ & $357^{\circ}$ & - & - & - & \\
$11 / 12 / 93$ & 0724 & 31 & SL-1 & $1,300^{\prime}$ & $347^{\circ}$ & - & - & - & \multirow{2}{*}{ Repeat } \\
$11 / 12 / 93$ & 0730 & 33 & SL-1 & $1,300^{\prime}$ & $360^{\circ}$ & - & - & - \\
$11 / 12 / 93$ & 0741 & 35 & River site & $1,300^{\prime}$ & $198^{\circ}$ & - & - & - & \\
\hline
\end{tabular}

Note: Headings have been adjusted by $+16^{\circ}$ in this summary to read "true"; logs read "magnetic." 


\begin{tabular}{|c|c|c|c|c|c|c|c|c|c|}
\hline \multicolumn{10}{|c|}{$\begin{array}{c}\text { Hanford Reservation Multispectral Scanner and Photo Summary } \\
\text { Daytime Coverage, November 18, } 1993 \\
\text { Daedalus AADS1268 Multispectral Scanner } \\
\text { Wild Heerbrugg RC-10 Aerial Mapping Camera }\end{array}$} \\
\hline Date & Time & Run & Line/Target & AGL & $\begin{array}{l}\text { True } \\
\text { Head }\end{array}$ & Perf \# & Frames & Scale & Comments \\
\hline $11 / 18 / 93$ & 1030 & 11 & Reflectance targets & $2,500^{\prime}$ & $351^{\circ}$ & 7615 & $01-14$ & $1: 5,000$ & Ch 12 sat., L crab \\
\hline $11 / 18 / 93$ & 1030 & 11 & $100 \mathrm{D} /-12$ (vis) & $2,500^{\prime}$ & $351^{\circ}$ & 7615 & $15-22$ & $1: 5,000$ & Ch 12 sat., L crab \\
\hline $11 / 18 / 93$ & 1047 & 13 & $200 \mathrm{E} /-17$ (vis) & $2,500^{\prime}$ & $356^{\circ}$ & 7615 & $23-39$ & $1: 5,000$ & Ch 12 sat., L crab \\
\hline $11 / 18 / 93$ & 1047 & 13 & $100 \mathrm{D} /-17$ (vis) & $2,500^{\prime}$ & $356^{\circ}$ & 7615 & $40-50$ & $1: 5,000$ & Ch 12 sat., L crab \\
\hline $11 / 18 / 93$ & 1104 & 15 & $200 \mathrm{E} /-7$ (vis) & $2,500^{\prime}$ & $357^{\circ}$ & 7615 & $51-65$ & $1: 5,000$ & \\
\hline $11 / 18 / 93$ & 1104 & 15 & $100 \mathrm{D} /-7$ (vis) & $2,500^{\prime}$ & $357^{\circ}$ & 7615 & $67-74$ & $1: 5,000$ & \\
\hline $11 / 18 / 93$ & 1122 & 17 & $200 \mathrm{E} /-2$ (vis) & $2,500^{\prime}$ & $357^{\circ}$ & 7615 & $75-91$ & $1: 5,000$ & \\
\hline $11 / 18 / 93$ & 1131 & 19 & $200 E /+3$ (vis) & $2,500^{\prime}$ & $358^{\circ}$ & 7615 & $92-106$ & $1: 5,000$ & \\
\hline $11 / 18 / 93$ & 1140 & 21 & $200 \mathrm{E} /-22$ (vis) & $2,500^{\prime}$ & $356^{\circ}$ & 7615 & $107-129$ & $1: 5,000$ & \\
\hline $11 / 18 / 93$ & 1149 & 23 & $200 \mathrm{~N} /$ visual & $2,500^{\prime}$ & $356^{\circ}$ & 7615 & $130-137$ & $1: 5,000$ & MSS data bad \\
\hline $11 / 18 / 93$ & 1149 & 23 & $100 \mathrm{~N} /$ visual & $2,500^{\circ}$ & $356^{\circ}$ & 7615 & $138-142$ & $1: 5,000$ & MSS data bad \\
\hline $11 / 18 / 93$ & 1158 & 25 & 200N/visual & $2,500^{\prime}$ & $354^{\circ}$ & 7615 & $143-150$ & $1: 5,000$ & Frame 147 center \\
\hline $11 / 18 / 93$ & 1158 & 25 & $100 \mathrm{~N} /$ visual & $2,500^{\prime}$ & $354^{\circ}$ & 7615 & $151-155$ & $1: 5,000$ & MSS data bad \\
\hline $11 / 18 / 93$ & 1209 & 27 & $100 \mathrm{~N} / \mathrm{west}$ & $2,500^{\prime}$ & $352^{\circ}$ & 7615 & $156-162$ & $1: 5,000$ & MSS data bad \\
\hline $11 / 18 / 93$ & 1219 & 29 & $200 \mathrm{~W} /+10$ (vis) & $2,500^{\prime}$ & $352^{\circ}$ & 7615 & $163-170$ & $1: 5,000$ & Off target, bad \\
\hline $11 / 18 / 93$ & 1229 & 31 & $200 \mathrm{~W} /+10$ (vis) & $2,500^{\prime}$ & $357^{\circ}$ & 7615 & $171-175$ & $1: 5,000$ & Repeat, off, bad \\
\hline $11 / 18 / 93$ & 1234 & 33 & $200 \mathrm{~W} /+5$ (vis) & $2,500^{\prime}$ & $354^{\circ}$ & 7615 & $176-192$ & $1: 5,000$ & MSS data bad \\
\hline $11 / 18 / 93$ & 1244 & 35 & $200 \mathrm{~W} /-4$ (vis) & $2,500^{\prime}$ & $356^{\circ}$ & 7615 & $193-213$ & $1: 5,000$ & MSS data bad \\
\hline $11 / 18 / 93$ & 1253 & 37 & 200W/0 (vis) & $2,500^{\prime}$ & $359^{\circ}$ & 7616 & $01-19$ & $1: 5,000$ & MSS data bad \\
\hline $11 / 18 / 93$ & 1300 & 39 & Reflectance targets & $2,500^{\prime}$ & $189^{\circ}$ & 7616 & $20-23$ & $1: 5,000$ & MSS data bad \\
\hline
\end{tabular}

Note: Headings have been adjusted by $+20^{\circ}$ in this summary to read "true"; logs read "magnetic." 


\begin{tabular}{|c|c|c|c|c|c|c|c|c|c|}
\hline \multicolumn{10}{|c|}{$\begin{array}{c}\text { Hanford Reservation Multispectral Scanner and Photo Summary } \\
\text { Daytime Coverage, November 19, } 1993 \\
\text { Daedalus AADS1268 Multispectral Scanner } \\
\text { Wild Heerbrugg RC-10 Aerial Mapping Camera }\end{array}$} \\
\hline Date & Time & Run & Line/Target & AGL & $\begin{array}{l}\text { True } \\
\text { Head }\end{array}$ & Perf \# & Frames & Scale & Comments \\
\hline $11 / 19 / 93$ & 1026 & 11 & $200 \mathrm{~W} / 0$ & $2,500^{\prime}$ & & - & - & - & \multirow{12}{*}{ Area $200 \mathrm{~W}$} \\
\hline $11 / 19 / 93$ & 1030 & 13 & Reflectance targets & $2,500^{\prime}$ & $188^{\circ}$ & 7616 & 28 & $1: 5,000$ & \\
\hline $11 / 19 / 93$ & 1051 & 15 & $200 \mathrm{~W} / 0$ & $2,500^{\prime}$ & $002^{\circ}$ & 7616 & $29-51$ & $1: 5,000$ & \\
\hline $11 / 19 / 93$ & 1100 & 17 & $200 \mathrm{~W} /+5$ & $2,500^{\prime}$ & $360^{\circ}$ & 7616 & $52-76$ & $1: 5,000$ & \\
\hline $11 / 19 / 93$ & 1107 & 19 & $200 W /-4$ & $2,500^{\prime}$ & $004^{\circ}$ & 7616 & $77-102$ & $1: 5,000$ & \\
\hline $11 / 19 / 93$ & 1117 & 21 & $200 \mathrm{~W} /+10$ & $2,500^{\prime}$ & $359^{\circ}$ & 7616 & $103-125$ & $1: 5,000$ & \\
\hline 11/19/93 & 1125 & 23 & $200 \mathrm{~W} /-9$ & $2,500^{\prime}$ & $359^{\circ}$ & 7616 & $126-148$ & $1: 5,000$ & \\
\hline $11 / 19 / 93$ & 1136 & 25 & $100 \mathrm{~B} /+5$ & $2,500^{\prime}$ & $359^{\circ}$ & 7616 & $149-158$ & $1: 5,000$ & \\
\hline $11 / 19 / 93$ & 1143 & 27 & $100 \mathrm{~B} / 0$ & $2,500^{\prime}$ & $002^{\circ}$ & 7616 & $159-168$ & $1: 5,000$ & \\
\hline $11 / 19 / 93$ & 1152 & 29 & $200 W /-14$ & $2,500^{\prime}$ & $360^{\circ}$ & 7616 & $169-194$ & $1: 5,000$ & \\
\hline $11 / 19 / 93$ & 1152 & 29 & $100 \mathrm{~B} /-5$ & $2,500^{\prime}$ & $360^{\circ}$ & 7616 & $195-200$ & $1: 5,000$ & \\
\hline $11 / 19 / 93$ & 1200 & 31 & $100 \mathrm{~B} /-5$ & $2,500^{\prime}$ & $360^{\circ}$ & 7616 & $201-213$ & $1: 5,000$ & \\
\hline $11 / 19 / 93$ & 1208 & 33 & $200 \mathrm{~N}$ & $2,500^{\prime}$ & $354^{\circ}$ & 7617 & $01-04$ & $1: 5,000$ & \multirow[t]{4}{*}{ Frame 2 centered } \\
\hline $11 / 19 / 93$ & 1215 & 35 & $100 \mathrm{~N}$ & $2,500^{\prime}$ & $360^{\circ}$ & 7617 & $05-12$ & $1: 5,000$ & \\
\hline $11 / 19 / 93$ & 1226 & 37 & $200 \mathrm{E} /-2$ & $2,500^{\prime}$ & $001^{\circ}$ & 7617 & $13-21$ & $1: 5,000$ & \\
\hline $11 / 19 / 93$ & 1234 & 39 & $200 \mathrm{E} /-7$ & $2,500^{\prime}$ & $002^{\circ}$ & 7617 & $22-30$ & $1: 5,000$ & \\
\hline $11 / 19 / 93$ & 1243 & 42 & $200 \mathrm{E} /-12$ & $2,500^{\prime}$ & $002^{\circ}$ & 7617 & $31-42$ & $1: 5,000$ & \multirow[t]{2}{*}{ Targets frame 33} \\
\hline $11 / 19 / 93$ & 1255 & 45 & River & $2,500^{\prime}$ & $043^{\circ}$ & - & - & - & \\
\hline $11 / 19 / 93$ & 1300 & 47 & $\begin{array}{l}\text { River, thermal } \\
\text { target }\end{array}$ & $2,500^{\prime}$ & $034^{\circ}$ & - & - & - & Repeat \\
\hline $11 / 19 / 93$ & 1309 & 49 & River & $2,500^{\prime}$ & $034^{\circ}$ & 7617 & $43-46$ & $1: 5,000$ & \multirow[t]{3}{*}{ Repeat } \\
\hline $11 / 19 / 93$ & 1325 & 51 & River/Leg 1 & $10,000^{\prime}$ & $035^{\circ}$ & 7617 & $47-58$ & $1: 20,000$ & \\
\hline $11 / 19 / 93$ & 1334 & 53 & River/Leg 2 & $10,000^{\prime}$ & $156^{\circ}$ & 7617 & $59-65$ & $1: 20,000$ & \\
\hline $11 / 19 / 93$ & 1352 & 55 & River/Leg 2 & $10,000^{\prime}$ & $146^{\circ}$ & 7617 & $66-83$ & $1: 20,000$ & \multirow[t]{2}{*}{ Repeat } \\
\hline $11 / 19 / 93$ & 1407 & 57 & River/Leg 3 & $10,000^{\prime}$ & $180^{\circ}$ & 7617 & $84-103$ & $1: 20,000$ & \\
\hline
\end{tabular}

Note: Headings have been adjusted by $+20^{\circ}$ in this summary to read "true"; logs read "magnetic." 


\begin{tabular}{|c|c|c|c|c|c|c|c|c|c|}
\hline \multicolumn{10}{|c|}{$\begin{array}{c}\text { Hanford Reservation Multispectral Scanner and Photo Summary } \\
\text { Nighttime Coverage, November } 20 \text { and } 21,1993 \\
\text { Daedalus AADS1268 Multispectral Scanner } \\
\text { Wild Heerbrugg RC-10 Aerial Mapping Camera }\end{array}$} \\
\hline Date & Time & Run & Line/Target & AGL & $\begin{array}{l}\text { True } \\
\text { Head }\end{array}$ & Perf \# & Frames & Scale & Comments \\
\hline $11 / 20 / 93$ & 2310 & 61 & River & $2,500^{\prime}$ & $216^{\circ}$ & - & - & - & \\
\hline $11 / 20 / 93$ & 2318 & 63 & River & $2,500^{\prime}$ & $218^{\circ}$ & - & - & - & Repeat \\
\hline $11 / 20 / 93$ & 1238 & 65 & River/Leg 2 & $10,000^{\circ}$ & $151^{\circ}$ & - & - & - & \\
\hline $11 / 20 / 93$ & 2354 & 67 & River/Leg 1 & $10,000^{\prime}$ & $042^{\circ}$ & - & - & - & \\
\hline $11 / 21 / 93$ & 0009 & 11 & $200 \mathrm{E} /-12$ & $2,500^{\prime}$ & $159^{\circ}$ & - & - & - & Abort \\
\hline $11 / 21 / 93$ & 0014 & 13 & $200 \mathrm{E} /-12$ & $2,500^{\prime}$ & $355^{\circ}$ & - & - & - & \\
\hline $11 / 21 / 93$ & 0024 & 15 & $200 W /-14$ & $2,500^{\prime}$ & $355^{\circ}$ & - & - & - & \\
\hline $11 / 21 / 93$ & $0030^{\circ}$ & 17 & $200 W /-9$ & $2,500^{\prime}$ & $184^{\circ}$ & - & - & - & \\
\hline $11 / 21 / 93$ & 0037 & 19 & $200 W /-4$ & $2,500^{\prime}$ & $356^{\circ}$ & - & - & - & \\
\hline $11 / 21 / 93$ & 0042 & 21 & $200 \mathrm{~W} / 0$ & $2,500^{\prime}$ & $188^{\circ}$ & - & - & - & \\
\hline $11 / 21 / 93$ & 0051 & 23 & $200 W /+5$ & $2,500^{\prime}$ & $357^{\circ}$ & - & - & - & \\
\hline $11 / 21 / 93$ & 0056 & 25 & $200 \mathrm{~W} /+10$ & $2,500^{\prime}$ & $189^{\circ}$ & - & - & - & \\
\hline $11 / 21 / 93$ & 0109 & 27 & $100 \mathrm{~B} /-16$ & $2,500^{\prime}$ & $354^{\circ}$ & - & - & - & $200 \mathrm{~W}$ axis \\
\hline $11 / 21 / 93$ & 0116 & 29 & $100 \mathrm{~B} /-11$ & $2,500^{\prime}$ & $354^{\circ}$ & - & - & - & $200 \mathrm{~W}$ axis \\
\hline $11 / 21 / 93$ & 0124 & 31 & $100 \mathrm{~B} /-6$ & $2,500^{\prime}$ & $354^{\circ}$ & - & - & - & $200 \mathrm{~W}$ axis \\
\hline $11 / 21 / 93$ & 0134 & 33 & $200 \mathrm{E} /-22$ & $2,500^{\prime}$ & $355^{\circ}$ & - & - & - & \\
\hline $11 / 21 / 93$ & 0141 & 35 & $200 \mathrm{E} /-17$ & $2,500^{\prime}$ & $187^{\circ}$ & - & - & - & $12^{\circ} \mathrm{drift}$ \\
\hline $11 / 21 / 93$ & 0153 & 37 & $200 \mathrm{E} /-12$ & $2,500^{\prime}$ & $357^{\circ}$ & - & - & - & \\
\hline $11 / 21 / 93$ & 0204 & 39 & $200 \mathrm{E} /-7$ & $2,500^{\prime}$ & $186^{\circ}$ & - & - & - & \\
\hline $11 / 21 / 93$ & 0214 & 41 & $200 \mathrm{E} /-2$ & $2,500^{\prime}$ & $353^{\circ}$ & - & - & - & \\
\hline $11 / 21 / 93$ & 0220 & 43 & $200 \mathrm{E} /+3$ & $2,500^{\prime}$ & $189^{\circ}$ & - & - & - & \\
\hline $11 / 21 / 93$ & 0229 & 45 & $200 \mathrm{~N}$ & $2,500^{\prime}$ & $351^{\circ}$ & - & - & - & \\
\hline $11 / 21 / 93$ & 0236 & 47 & $100 \mathrm{~N} /-24$ & $2,500^{\prime}$ & $191^{\circ}$ & - & - & - & $200 \mathrm{E}$ axis \\
\hline $11 / 21 / 93$ & 0240 & 49 & $100 \mathrm{~N} /-32$ & $2,500^{\circ}$ & $348^{\circ}$ & - & - & - & $200 \mathrm{E}$ axis \\
\hline
\end{tabular}

Note: Headings have been adjusted by $+20^{\circ}$ in this summary to read "true"; logs read 'magnetic." 


\section{APPENDIX B}

\section{SURVEY PERSONNEL}

$\begin{array}{ll}\text { J.E. Shines } & \text { Mission Manager } \\ \text { S.B. Brewster, Jr. } & \text { Lead Analyst - INEL } \\ \text { M.E. Howard } & \text { Lead Analyst - Hanford } \\ \text { T.L. McCreary } & \text { Acquisition Scientist } \\ \text { G.E. Menkel } & \text { MSS Technician } \\ \text { V.A. Young } & \text { MSS Technician } \\ \text { M.A. Rivera } & \text { Photo Technician } \\ \text { G.M. Butler } & \text { Pilot-in-Command } \\ \text { S.L. Bartley } & \text { Pilot } \\ \text { C.E. Peterson } & \text { Aircraft Mechanic }\end{array}$




\section{REFERENCES}

1. Estes, J.E., E.J. Hajic and L.R. Tinney. "Fundamentals of Image Analysis: Analysis of Visible and Thermal IR Data," from The Manual of Remote Sensing, Vol. I, Second Edition.

American Society of Photogrammetry and Remote Sensing, Falls Church, Virginia, 1983, pp 1097-1101.

2. Best, R.G., S.B. Brewster, Jr., E.L. Doak, and J.E. Shines. A Multispectral Scanner Survey of the United States Department of Energy's Rocky Flats Plant, Golden, Colorado, EG\&G/EM Letter Report MRSD-8902, Las Vegas, Nevada, September 1989.

3. Estes, pp 1039-1041.

4. Swain, P.H., and S.M. Davis, eds. Remote Sensing: The Quantitative Approach. McGraw Hill, Inc., New York, New York, 1978, pp. 347-353. 
DOE/DP

L.E. Gordon-Hagerty

O.W. Taylor

(1)

(1)

EG\&G/EM

S.B. Brewster LVAO

J.F. Doyle LVAO

M.E. Howard LVAO

W.M. Quam SBO

J.E. Shines LVAO

G.R. Shipman WAMO

L.R. Tinney LVAO

W. J. Tipton LVAO

P.H. Zavattaro LVAO

(1)

(1)

(1)

(3)

\section{LIBRARIES}

RSL

SIGIS

DOE/NV

(1)

TIC

WAMO
(5)

(1)

(1)
(1)
(13) 